Historic, archived document

Do not assume content reflects current scientific knowledge, policies, or practices. 



\section{TOBACCO in the}

UNITED

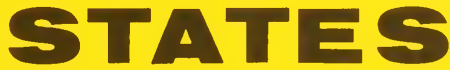

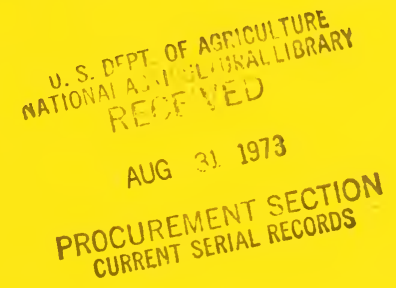

\section{- PRODUCTION}

\section{- MARKETING}

\section{- manufacturing}

\section{- EXPORTS}

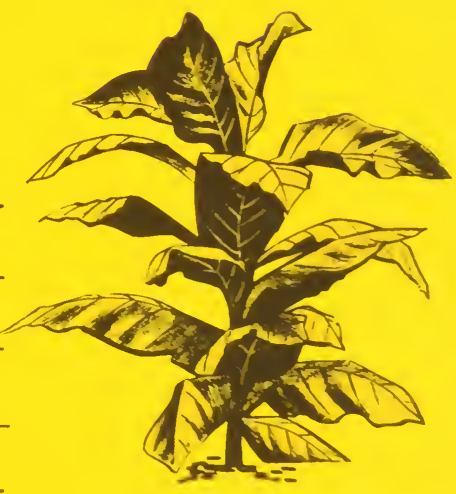





\section{T O B A C C O \\ In the \\ UN I TED STATES}

UNITED STATES DEPARTMENT OF AGRICULTURE

AGRICULTURAL MARKETING SERVICE

Revised January 1973

\section{P U R POSE}

This pamphlet has been compiled to fill a need for a brief but comprehensive description of the various phases of the tobacco industry. It is designed mainly for use of persons whose frequent requests indicate an interest in such overall type of information. The publication contains a minimum of statistics. For current statistical information, reference should be made to the latest editions of the Annual Report on Tobacco Statistics, published by the Agricultural Marketing Service, and the Tobacco Situation, published by the Economic Research Service.

The material has been taken primarily from the publications listed as "principal sources" in the bibliography, and brought to date as required. Additional comments have been added, based on first-hand observations and experience, and contributions from industry sources. 



\section{P R E F A C E}

Tobacco is a commodity that is of major importance to United States agriculture and business. It usually ranks fifth among field crops in cash receipts to farmers, and is fifth in value among agricultural export classifications. It is a major source of revenue for Federal, State, and local governments (receipts totaled over 4.7 billion dollars for the fiscal year 1970-71). About 2 percent of consumer expenditures goes for tobacco products (12.5 billion dollars in 1971).

\section{CONTENTS}

Historical sketch

Classification

Culture .

Harvesting and curing ..............

Marketing. ................. 28

Storage and aging............... . . . 38

Manufacturing industry ............ . . . 45 45

International Trade .................... 56

United States exports ................... 58

Referen ce guide for tobacco information........ 61

Bibliography .................... 62

This publication first appeared in 1962 through the efforts of Albert Doub, Jr., and Alice liolfe. The second and third editions were prepared by Albert Doub, Jr., and Larry Crabtree. 



\section{HISTORICAL SKETCH}

Tobacco is one of the products given to the world by the natives of the Americas. At the time of the discovery of America, Columbus found the natives using tobacco in the forms common today--smoking, chewing, and snuff. Early records show that they also understood the essential features of modern production, topping and suckering the plants, and the distinctive drying processes, now known as air-curing, sun-curing, and fire-curing. Facts regarding the introduction of tobacco to the Europeans by the Indians, the attention given it in the literature of history, poetry, and romance, and its pervasive influence in the social and economic affairs of mankind have made this crop unique among the products of the soil.

The rapidity of the expansion of tobacco production over the world was phenomenal. By 1531, less than 40 years after the discovery of America, Spaniards were cultivating the crop commercially in the West Indies; by 1560 , it was being grown in Europe as an ornamental plant and for its medicinal qualities; by 1580, its comnercial culture had extended to Cuba and Venezuela, and by about 1600 , to Brazil. By 1600 or 1605 , mariners and traders had introduced it into China, Japan, South Africa, and many other countries.

History records that John Rolfe in 1612 began the commercial culture of tobacco in the English colonies at Jamestown, and that in 1613, a small shipment was made to England. But tobacco from the Spanish settlements was used in Europe and the British Isles at least 20 years before the Virginia colony was founded. This meant that at the outset the tobacco produced by the colonists was forced to meet the competition of the Spanish product in the export market. In spite of this, however, the growing of tobacco soon became general in the Virginia colony and production increased rapidly. It became the leading item of commerce with the mother country, for it was about the only commodity the settlers could produce to exchange for the many essential manufactured products needed from England.

From historical records of the era, we learn that tobacco was such a major factor in the economy of the colony at one time that John Rolfe was growing it in the streets of Jamestown, and that wives were bought and ministers paid with specified quantities of it.

In colonial days, the only market for tobacco was, of course, the export trade. In the seventeenth century, the usual method of marketing was to consign the tobacco, packed in hogsheads, to an English merchant, who sold it on a commission basis and supplied needed manufactured goods in return. This system proved generally unsatisfactory to the planter, both because of the delay involved in the transaction and the risk encountered in dealing with the often unscrupulous English merchants. During the course of the eighteenth century, another method of marketing came into general use, by which the crop was sold at the farm to a local British agent, who maintained a "store," where the planter might secure the manufactured items he needed. This system proved to be more satisfactory and became the most popular way of marketing. 
It was not until after the end of the Revolutionary War that the use of tobacco in domestic manufacture first assumed importance in this country. Presently, about 70 percent of a tobacco crop is used domestically in the production of cigars, cigarettes, and other forms of manufacture. Today, about 95 percent of the tobacco produced in the United States is sold to the highest bidder in the auction warehouses. Bidders are usually manufacturers and dealers who buy the leaf for use in the manufacture of the various products, or for export.

The tobacco in common use today is very unlike that which the settlers found growing in the Indian villages along the James, Rappahannock, and other rivers of Tidewater Virginia. Most of this tobacco was a strong type belonging to the species Nicotinia rustica L., believed to have originated in Mexico. The English colonists learned of the milder and more aromatic varieties of the species Nicotinia tabacum L., which probably originated in Brazil, and in time they adopted this kind for their production.

The growing of tobacco in Maryland began in the 1630's. During the eighteenth century, Virginia and Maryland grew the bulk of the country's crop. At the outbreak of the Revolutionary War, exports were about 100 million pounds annually, nearly all of which was produced in Virginia and Maryland. Soon after the War, culture was extended into Kentucky, Tennessee, Ohio, Missouri, and North Carolina. Today it is also grown commercially in South Carolina, Georgia, Florida, Alabama, Indiana, West Virginia, Pennsylvania, Connecticut, Massachusetts, Wisconsin, and Louisiana.

As tobacco culture was carried from the first settlement at Jamestown into new territory, it was seen that the changes in soil and climate caused important differences in the characteristics of the tobacco produced. Gradually it became apparent that these differences in the properties of the tobacco leaf greatly affected its suitability for use in different manufactured forms. Through gradual evolution, tobacco culture has become highly specialized. Each district produces a special type of leaf particularly adapted for certain uses: cigarettes, cigars, smoking or chewing tobacco, and snuff. It has been found that special types of tobacco can be produced only under certain conditions of soil and climate, by using certain varieties, and by following special methods in growing and curing the crop.

From the beginning made by John Rolfe at Jamestown, tobacco production, marketing, and use have contributed important chapters to American history.

Currently about 450,000 farm families in the United States and Puerto Rico grow tobacco for sale. Total annual gross income to farmers from the crop is 1.2 billion dollars. Tobacco growing requires a great deal of labor. A farmer and his family (or hired workers) must put in about 250 man-hours or more to raise one acre of tobacco. This may be contrasted to the average amount of labor--about 3 hours--needed to raise an acre of wheat. Tobacco farmers say there is a thirteenth month in their calendar year, "Tobaccuary," made up of all the extra hours they have to work--before dawn and after dark-to produce a tobacco crop. 


\section{CLASSIFICATION}

Since the various tobacco products require leaf of different characteristics, a standard system of classification is necessary. This is used for orderly marketing and distribution of the leaf from farmers to manufacturers and dealers. The Department of Agriculture designates six major classes of tobaccos grown in the United States. Differences between classes come chiefly from variations in soils and climate, varieties of seed, cultural practices, and curing methods. The first three classes are named on the basis of the method used in curing; the last three, which are all cigar leaf classes, on the basis of the principal use for which they are produced.

Tobaccos grown in the United States, along with the States in which they are grown, are listed below, according to the classification of the Department of Agriculture.

\section{CLASSIFICATION OF TOBACCO GROWN IN THE UNITED STATES}

Class

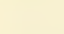

1. Flue-cured

2. Fire-cured

(a) Light

3. Air-cured

(b) Dark

4. Cigar-filler

5. Cigar-binder

6. Cigar-wrapper

7. Miscellaneous Domestic
Type

11 (a) 0ld Belt

11 (b) Middle Belt

12

13

14

21

22

23

31

32

35

36

41

42-44

46

51

52

54

55

61

62

72

Border Belt

Virginia

Burley

One Sucker

Green River

Ohio filler

Perique
Eastern Belt

Georgia \& Florida Belt

Eastern District

Western District

Maryland Broadleaf

Virginia sun-cured

Pennsylvania Seedleaf

Puerto Rican filler

Connecticut Broadleaf

Connecticut Havana Seed

Southern Wisconsin

Northern Wisconsin

Connecticut Shade

Georgia \& Florida Shade
States in which grown

Va. and N.C.

N.C.

N.C.

S.C. and N.C.

Ga., Fla., and Ala.

Va.

$K y$. and Tenn.

$K y$. and Tenn

Ky., Tenn., Ohio, Ind. Va., N.C., W.Va., Mo.

Md.

Ky. and Tenn

Ky.

Va.

$\mathrm{Pa}$.

Ohio

Puerto Rico

Conn.

Conn. and Mass.

Wis.

Wis.

Conn. and Mass

$\mathrm{Ga}$. and Fla.

La . 
Each class is made up of two or more different types. Differences among types are found in color, body, leaf composition, and in the response to fermentation and aging. They result mainly from varying soil and climatic conditions, since the varieties and growing and curing methods for all types within a class are generally similar. Within the flue-cured class individual types can no longer be easily identified and the type designation usually refers only to a marketing area.

Each type is further subdivided into grades. However, one set of standards is applied to all types of flue-cured, and some types of dark and cigar tobaccos share standards. These grades are related to group or stalk position, quality, color, and other characteristics. One type of tobacco may be subdivided into over 100 different grades, whereas others may have on 1 y 5 or 6 grades. Manufacturers buy the various leaf grades according to the intended use in manufacture.

Leaves vary greatly in size. They range in length from about 12 to 30 inches, but most are 20 to 24 inches long. The width is usually about onehalf the length, varying according to the different types. Leaves of some types have sharp, pointed tips, and others are rounded.

Following is a brief description of tobacco classes, covering some of the elements of quality, volume of production and exports, and principal uses.

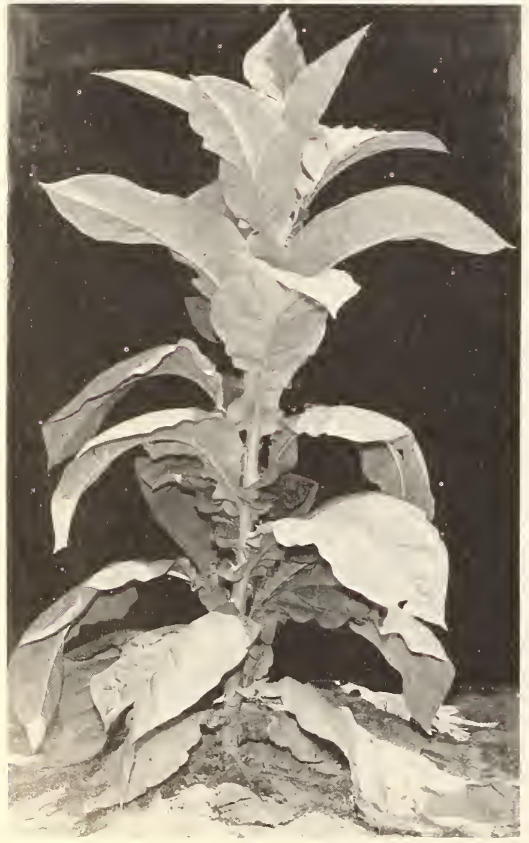

Class 1 - Flue-cured makes up

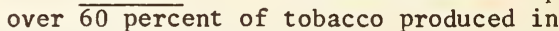
the United States today. Its name comes from the metal flues of the heating apparatus originally used in curing barns. It is yellow to reddishorange in color, thin to medium in body, and mild in flavor.

Flue-cured tobacco is the principal export type, accounting for over 83 percent of the total leaf exported. Over one-third of the production is exported, or around 500 to 530 million pounds annually.

Most of the crop is used in cigarettes, both in the United States and in the importing countries. Cigarettes account for 95 percent of flue-cured usage in the United States, smoking and chewing tobacco accounting for the remainder.

\section{Figure 1.--Flue-cured plant topped and} ready for barvest.

BN-39192 
Class 2 - Fire-cured is medium to heavy in body, light to dark brown in color, and strong in flavor. It is so-called because of the smoky flavor and aroma it receives from "firing" it over open fires in the curing barns. It is used for making snuff, roll and plug chewing tobacco, strong cigars, and heavy smoking tobacco. Production currently amounts to around $40 \mathrm{million}$ pounds annually, over half of which is exported.

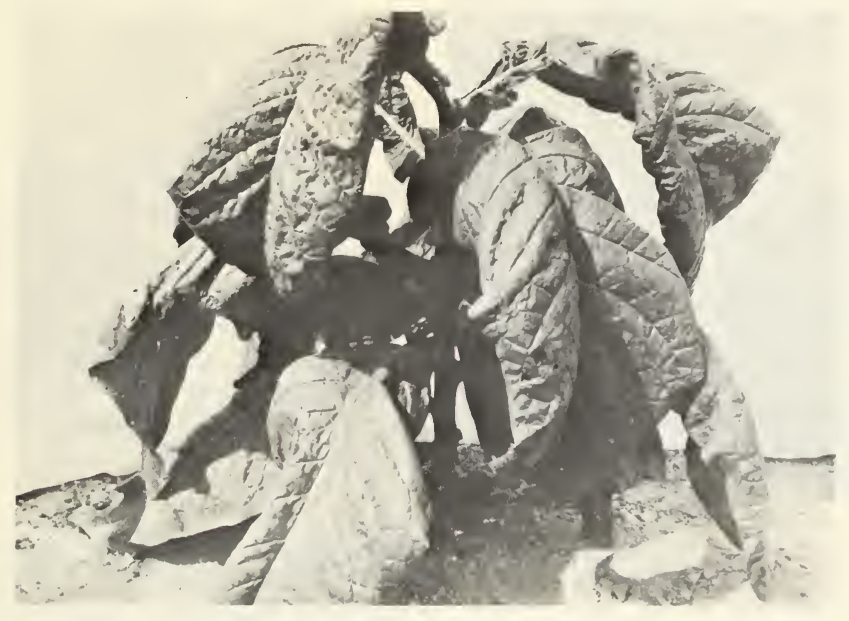

BN-9588

Figure 2.--Kentucky-Tennessee Fire-cured plant. Fire-cured is also grown in Virginia.

Class 3 - Air-cured is so-called because it is cured under natural atmospheric conditions, usually without the use of supplementary heat, except to prevent pole-rot, house-burn or barn-burn in damp weather.

(a) Light air-cured is normally very thin to medium in body, light $t$ an shaded toward red to reddish brown in color, mild in flavor, and is used chiefly in making cigarettes. It is usually combined with flue-cured and small quantities of imported or "Turkish" tobacco to form the blends for cigarette manufacture. Each of the two types, burley and Maryland, has special characteristics.

(See following page for descriptions of burley and Maryland.)

(b) Dark air cured is medium to heavy-bodied and ranges from light to medium brown in color. It is used in the manufacture of the same products as the fire-cured types--mainly for chewing tobacco and snuff, but also to some extent for smoking tobacco and cigars. Annual production is decreasing, and now amounts to 16 to $18 \mathrm{million}$ pounds. Exports are about 3 million pounds a year. 


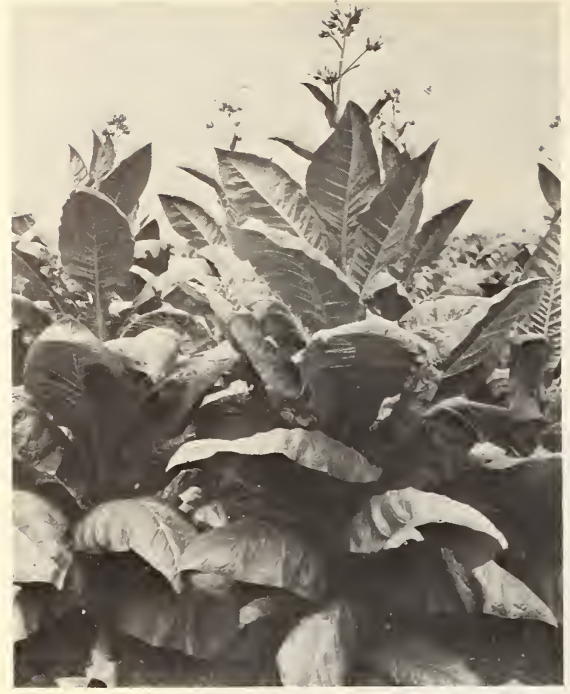

BN-78283

Figure 3.--Burley plant with flower beads. Growers normally break off the flowers for better development of the leaves.

Maryland is usually thought to be about ideal as to its burning qualities in the manufactured form. This is one of the important reasons for its use in cigarette blends. Production has averaged about $28 \mathrm{million}$ pounds annually in recent years. Exports have been declining and now total 10 to $12 \mathrm{million}$ pounds a year.

Figure 4.--A typical plant of Maryland tobacco just prior to barvest.
Burley, on an area basis, is the most widely grown single type in the United States. It is produced in eight States, and about 550 million pounds are produced annually--more than one-fourth of all the tobacco grown in this country.

Burley is desired for its flavor and aroma for cigarette blends. Cigarettes currently account for nearly 90 percent of the domestic consumption of bur1ey. In addition to its use in cigarettes, it also goes into the manufacture of pipe tobaccos, and plug and twist chewing. Exports have ranged between 50 and 60 million pounds annually in recent years.

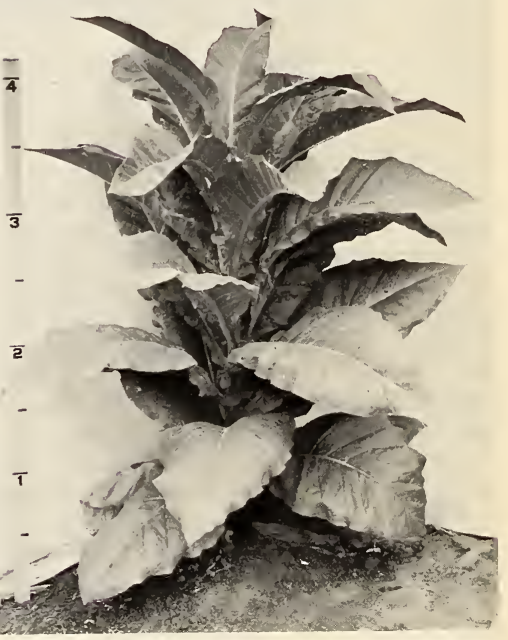

BN-16541 
Classes 4-6, cigar leaf tynes, are classified according to the principal use of the tobacco--as filler, binder, or wrapper. However, wrapper types may be used for all three purposes, and some grades from any type may go into loose-leaf chewing. Cigar tobaccos are air-cured with the excention of a small portion of the wrander types cured with heat to produce a greenish leaf commonly known as Candela leaf. Production is declining and is now about 73 million pounds. Exports are around 2 to 4 million pounds.

The cigar-filler types of tobacco are of medium to heavy body. Their main use is in the core or body of the cigar. For this purpose, the principal factors to be considered are flavor, aroma, and burning quality.

The cigar-binder types were originally used mainly for binding the bunched filler into the form and shape of the cigar. Natural leaf binders must have good burning quality, aroma, and elasticity. However, practically all cigars now use a reconstituted tobacco sheet for the inner binder. As a result, loose leaf chewing tobacco is now the principal outlet.

Cigar wrappers are the most difficult and expensive of all tobaccos to grow. They are used primarily for the outside cover on cigars, and leaves must be elastic, free of injury, uniform in color, and have good burning qualities. They should also be very thin, smooth, and of fine quality. In order to produce leaves with such proderties, it is necessary to protect them against the sun and the extremes of weather. So the fields are enclosed with a framework covered with cloth (fig. 5). This cloth screening filters the sunlight and creates an artificial environment favorable to the specialized product desired. These types are commonly called "shade-grown" as descriptive of this method of cultivation. Most cigars continue to be made with a natural wrapper but the use of reconstituted tobacco sheet is increasing.
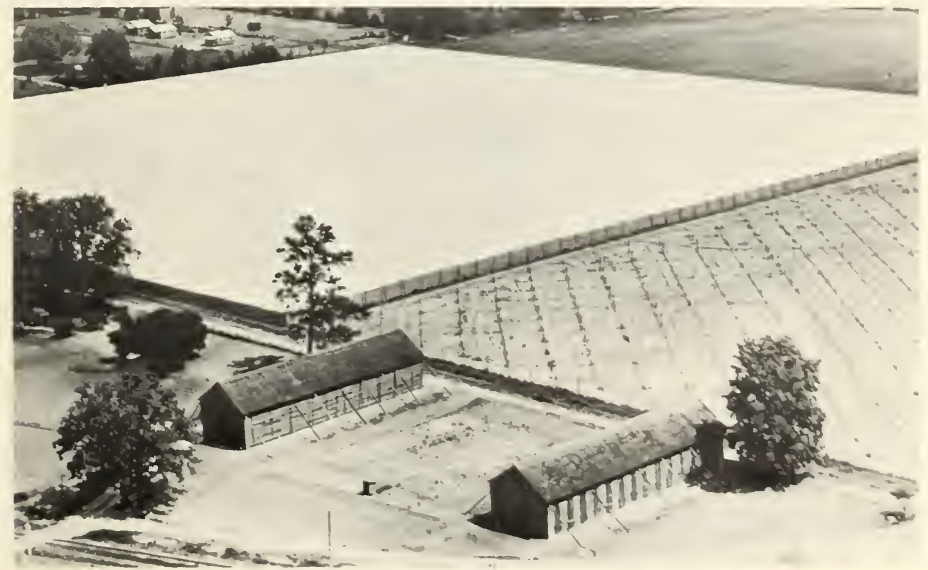

Figure 5.--Aerial view of shade tobacco teut and barns in Florida. 
Perique. In addition to the major classes, some "miscellaneous" types of tobaccos are grown. The most important of these is Perique (type 72). It is grown on a narrow strip of land in St. James Parish in Louisiana, and comprises only a very small part of total United States production. This unique trpe of tobacco is noted for its pleasing aroma. Small quantities are used in blends in the manufacture of fancy smoking tobacco. Annual production is around 170 thousand pounds, and a large percentage is exported.

The following table shows, by kinds, the approximate normal volume of production percentages used domestically and exported, and the usage in manufactured products used.

Volume of production, domestic disappearance and exports, and domestic usages in manufactured products, by kinds.

\begin{tabular}{|c|c|c|c|c|c|c|}
\hline \multirow{3}{*}{$\mathrm{Class}$} & : Typical & \multirow{2}{*}{$\begin{array}{l}\text { production: } \\
\text { Percentage: } \\
\text { of total : }\end{array}$} & \multicolumn{2}{|c|}{ Disappearance } & \multirow{2}{*}{$\begin{array}{l}: \text { Usage } \\
: \text { Principal }\end{array}$} & \multirow{2}{*}{$\begin{array}{lc}\text { in } & \text { products } \\
: & \text { Other } \\
: & \\
\end{array}$} \\
\hline & : Quantity & & : Domestic & Exports: & & \\
\hline & $\begin{array}{l}\text { :Million } \\
\text { :pounds } \\
\end{array}$ & Percent & Percent & Percent & & \\
\hline Flue-cured... & $\begin{array}{l}: 1,080 \\
:\end{array}$ & 61.1 & 55 & 45 & Cigarettes & $\begin{array}{l}\text { Smoking, chew- } \\
\text { ing }\end{array}$ \\
\hline Fire-cured... & : & 2.3 & 41 & 59 & Snuff & $\begin{array}{l}\text { Chewing, strong } \\
\text { cigars }\end{array}$ \\
\hline Air-cured: & $:$ & & & & & \\
\hline Burley.... & 530 & 30.0 & 90 & 10 & Cigarettes & $\begin{array}{l}\text { Smoking, chew- } \\
\text { ing }\end{array}$ \\
\hline Maryland.. & 27 & 1.5 & 70 & 30 & Cigarettes & Cigar filler \\
\hline Dark...... & 17 & 1.0 & 80 & 20 & Chewing & $\begin{array}{l}\text { Smoking, snuff, } \\
\text { cigar filler }\end{array}$ \\
\hline Cigar filler. & 40 & 2.3 & 99 & 1 & $\begin{array}{l}\text { Cigar } \\
\text { filler }\end{array}$ & $\begin{array}{l}\text { Loose-leaf } \\
\text { chewing }\end{array}$ \\
\hline Cigar binder. & 20 & 1.1 & 95 & 5 & $\begin{array}{l}\text { Loose-leaf } \\
\text { chewing }\end{array}$ & Cigar binder \\
\hline Cigar wrapper & 12 & .7 & 85 & 15 & $\begin{array}{l}\text { Cigar } \\
\text { wrapper }\end{array}$ & $\begin{array}{l}\text { Lonse-leaf } \\
\text { chewing }\end{array}$ \\
\hline Total & : 1,766 & 100.0 & 68 & 32 & & \\
\hline
\end{tabular}




\section{TOBACCO}

\section{AUCIION MARKETS AND PRODUCING AREAS}

(CIGAR IEAF PRODUCING AREAS NOT SHOWN)

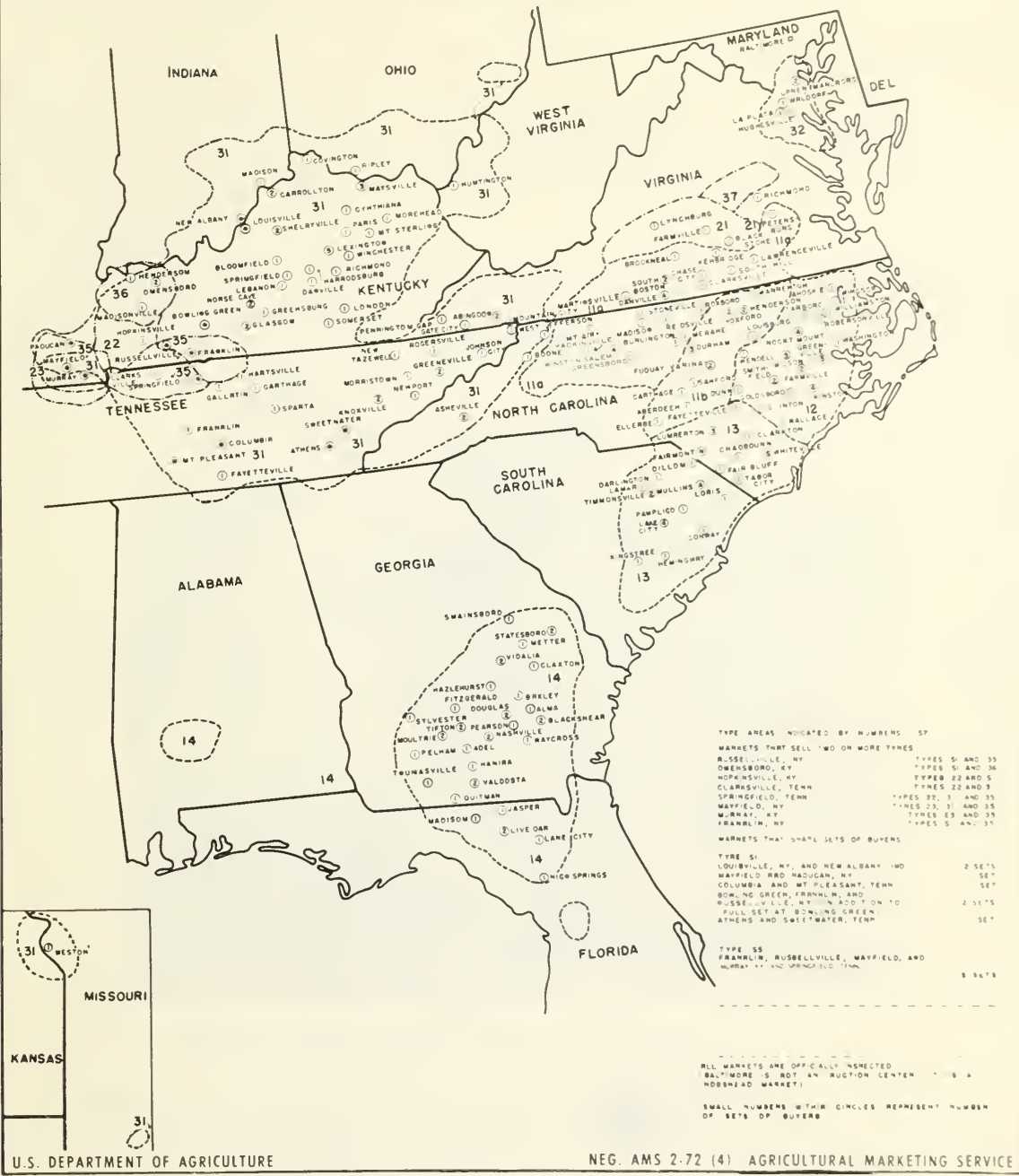




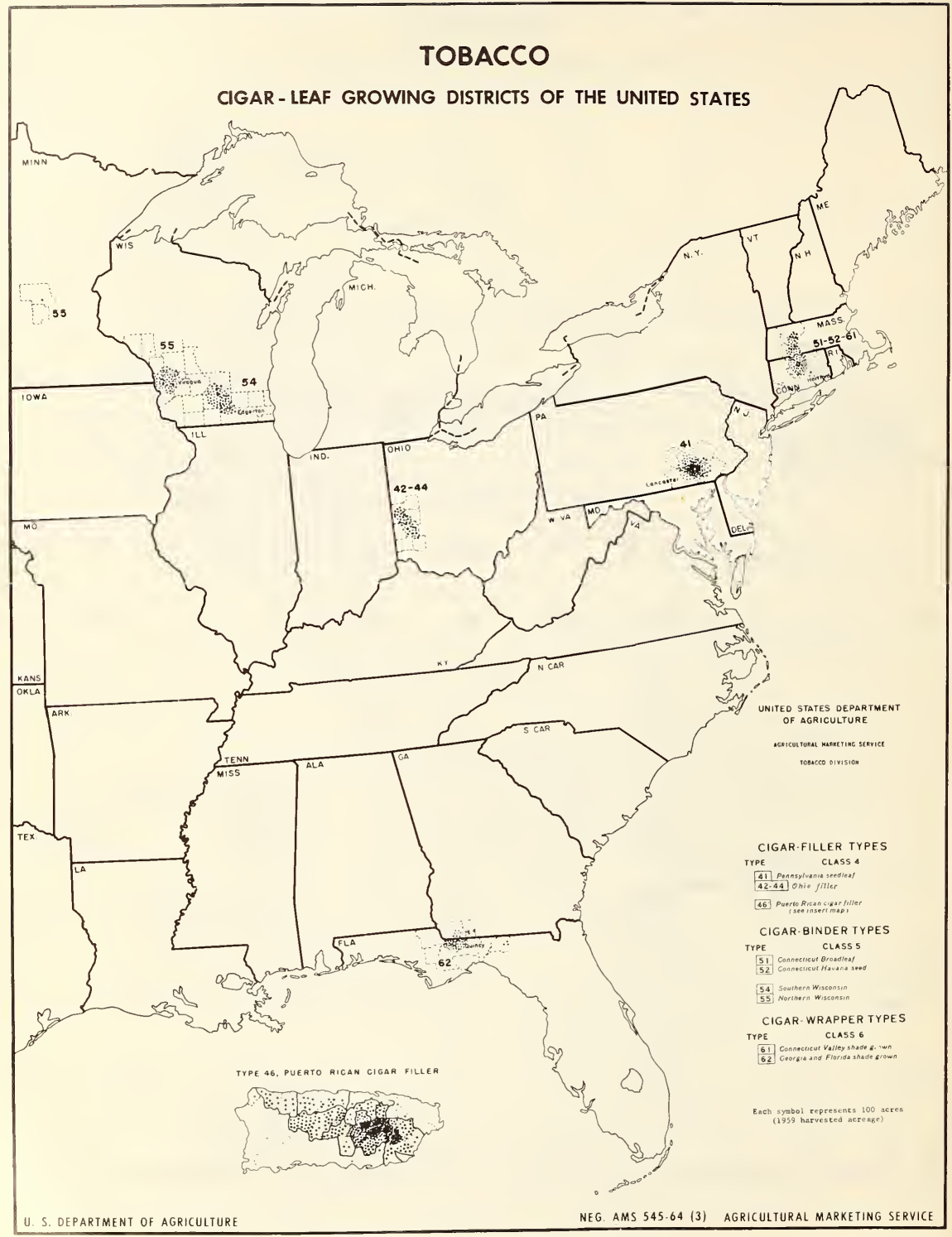




\section{CULTURE}

The various types of tobacco are grown in well-defined localities where soil and climate have been found to yield a product with properties desired for manufacture or export. In addition, the methods of growing and handling are also determined by the kind of leaf required by the trade.

Yield per acre. The market weight of tobacco ranges from 1,000 to 2,600 pounds per acre, depending on the type, with the average for all United States tobacco about 2,100 pounds. The trend during the last ten years has been toward greater yields to offset higher production costs. From 1960 to 1970 the average yield rose from 1,700 to 2,100 pounds per acre. However, with the poundage control programs for flue-cured and burley this upward trend is not likely to continue.

Seeding. Tobacco seedlings are grown in seedbeds which are covered with cloth or plastic (fig. 8). The seeds are so tiny that one ounce contains about 300 to 350 thousand seeds. A sixth to an eighth of an ounce of seed is enough to sow 100 square yards of seedbed, and will furnish enough plants to set 3 or 4 acres in the field. For security, many growers will sow about 100 square yards of seedbeed for each acre to be set in the field.

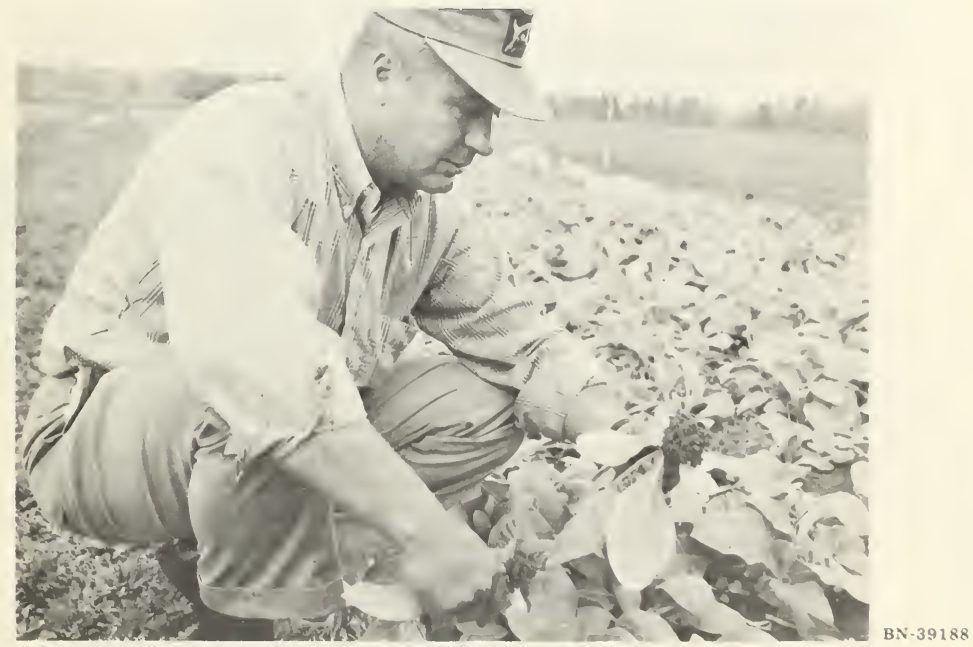

Figure 6.--Burley Seedlings ready for transplanting to the field.

Seeding may be done with a mechanical seeder or by mixing the seed with clean sand, pulverized fertilizer, ashes, or lime before sowing. Germination begins when the temperature reaches about $65^{\circ}$. The plants are ready for transplanting to the fields when they have developed 6 to 8 leaves and are 6 to 8 inches high. 

binder and wrapper types, is grown on sandy to clay loam with a sandy or sandy clay subsoil. Cigar filler, burley, and fire-cured are grown on silt loam and clay loam soils, with clay subsoils.

Proper fertilization is an important factor in producing the specific kind of leaf desired. The farmer must know the exact kinds and amounts of fertilizers for his particular kind of soil. For instance, the quantity of nitrogen, which stimulates rapid growth, is of critical importance for fluecured, but is not so important for burley and Maryland. A liberal supply of potash, in the form of sulfate, carbonate, or nitrate, reduces the susceptibility to bacterial leaf spot diseases, and also improves the "burning quality" of the tobacco. The excessive use of chlorides in any form impairs the burning quality. Barnyard manures, when available, are used to considerable extent in some types, such as burley and Wisconsin, but very sparingly in the flue-cured and some other areas. The development of the plant is seriously affected if any one of the chemical elements necessary for its growth is lacking in the soil.

Transplanting. Dates for transplanting range from about March 20 to early May in Georgia and Florida, South Carolina, and eastern North Carolina, and from May 1 through June in the other growing areas. Just before the plants are to be set, the final preparation of the field is made by repeated disking and rolling or harrowing, and smoothing and furrowing the surface soil. Sometimes the field is left level, and sometimes it is ridged and the plants set on the ridges. Ridging is the prevailing practice in flue-cured and, to some extent, in the dark types, and level culture is chiefly used in the cigar types, burley, and Maryland.

Two methods are used in transplanting the tobacco seedlings into the field: (1) by power driven machine; (2) by use of a hand transplanter.

(1) The power-drawn transplanting machine is the most widelyused method for planting today, especially on the larger farms (fig. 7). It is operated by a driver, and carries two, four, or eight "setters," who ride in low back seats and alternate in placing the plants on a wheel mechanism which spaces them at the proper intervals in the row. The machine opens the furrow, dumps a measured quantity of water, and draws the soil about the roots of the plants.

(2) The hand transplanter is still used, but mostly on the smaller farms. It is a device of lightweight metal, about 3-1/2 feet in length, cone-shaped at the bottom, and with a handle at the top. It carries a water supply, and has an opening through which the plant is dropped. It makes a hole in the soil, and with one operation of the handle, drops the plant, and releases the proper quantity of water. The worker sets the plant by pressing the soil around it with his foot. 


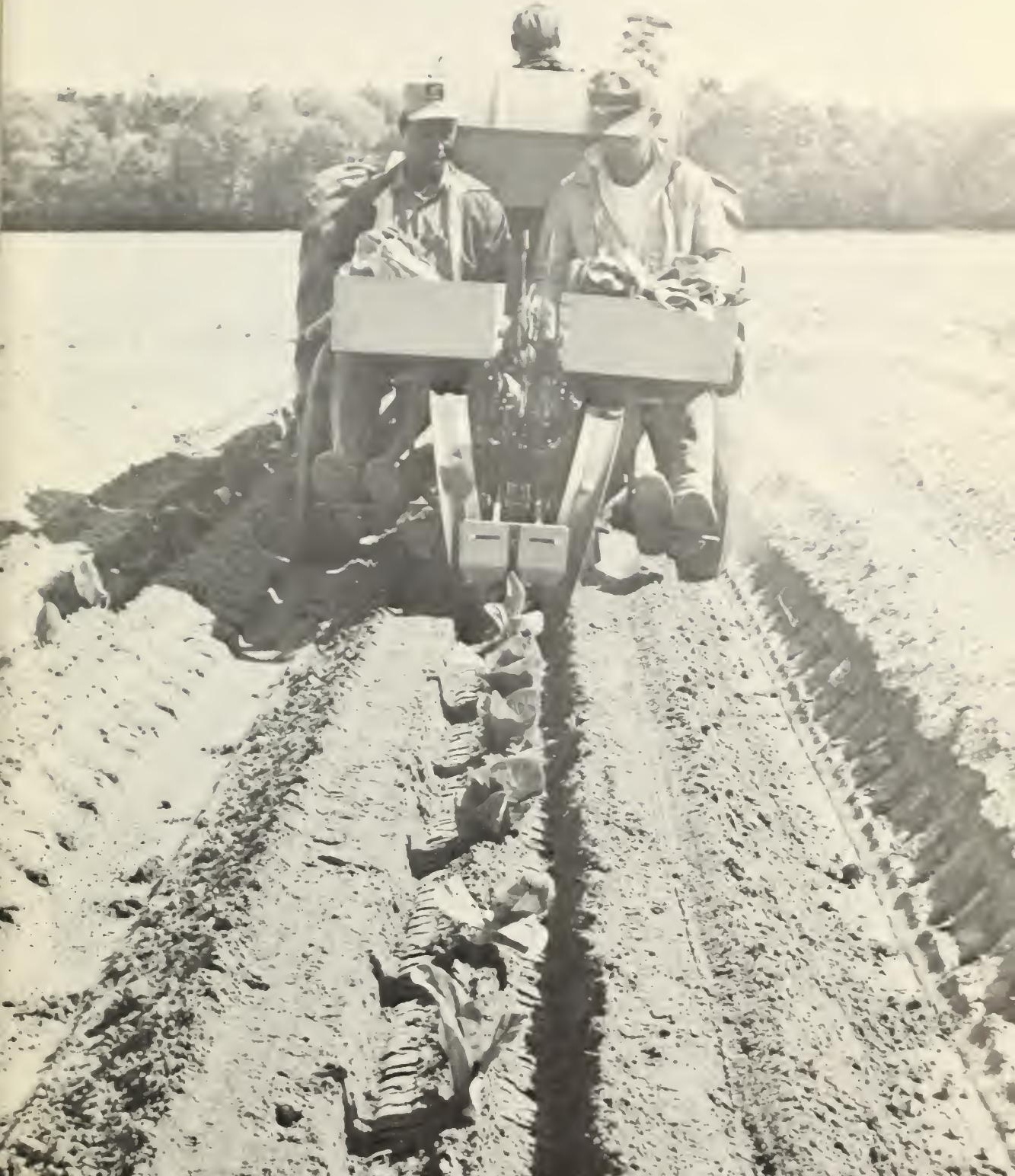


The spacing of plants in the fields differs widely among types and classes. The width between rows averages 3 to 4 feet, with the plants 12 to 24 inches apart in the rows. This spacing allows for 5,000 to 11,000 plants per acre.

The cultivation methods of tobacco crops are similar to those practiced for other row crops. The main purpose is to keep the soil loose and eliminate weeds and grasses. The soil must be well drained and aired. Two to four cultivations are made on most types, the last one being when the tobacco is about knee high.

Topping. When the plant begins to mature and produce flowers, it is topped by breaking or cutting off the upper portion of the plant at about the third leaf below the flower. This allows the remaining leaves to draw additional nutrients and thus become larger, thicker, and heavier. Upon removal of the flower lateral buds or "suckers" begin to develop and grow in the leaf axils in an attempt to replace the terminal bud. Since the purpose of topping is to increase the size and weight of the leaves, these suckers must be removed at intervals either by hand or controlled by the use of chemicals. The time and height of topping can have great effects on the yield and quality of the cured leaf and are among the most critical decisions the grower must make.

The number of leaves remaining on the plant after topping usually varies from 18 to 26 in the flue-cured, Maryland, burley, and cigar types, and about 14 in the fire-cured and dark air-cured types.

\section{HARVESTING AND CURING}

Harvesting

When the crop is mature, 60 to 90 days after transplanting, it is harvested by one of two methods: (1) by "priming," in which the leaves are picked individually from the plant as they ripen; or (2) by "stalk-cutting," in which the entire plant or stalk is cut.

Much of the success in curing tobacco depends on its being harvested at just the right stage of maturity--neither too ripe nor too green. This is a critical point in the production of good quality tobacco. The leaves begin to turn a yellowish color as they mature and it takes an experienced eye to recognize the proper stage of ripeness. Such experience is gained only through long years of growing and harvesting tobacco crops.

The harvesting of tobacco is still accomplished by hand labor. True, mechanical harvestors are now available for flue-cured tobacco, but the costs and reliability of such a specialized machine prohibits widespread use of these machines on small acreages.

(1) Priming. Flue-cured and cigar wrapper tobaccos are harvested by the priming method (figs. 8,9,\&12). Puerto Rican filler is also harvested almost entirely in this way. Beginning at the bottom, two to four leaves are picked from the stalk at a time. The fields are gone over 4 to 6 times at weekly intervals to get all the leaves at the right stage of ripeness. 


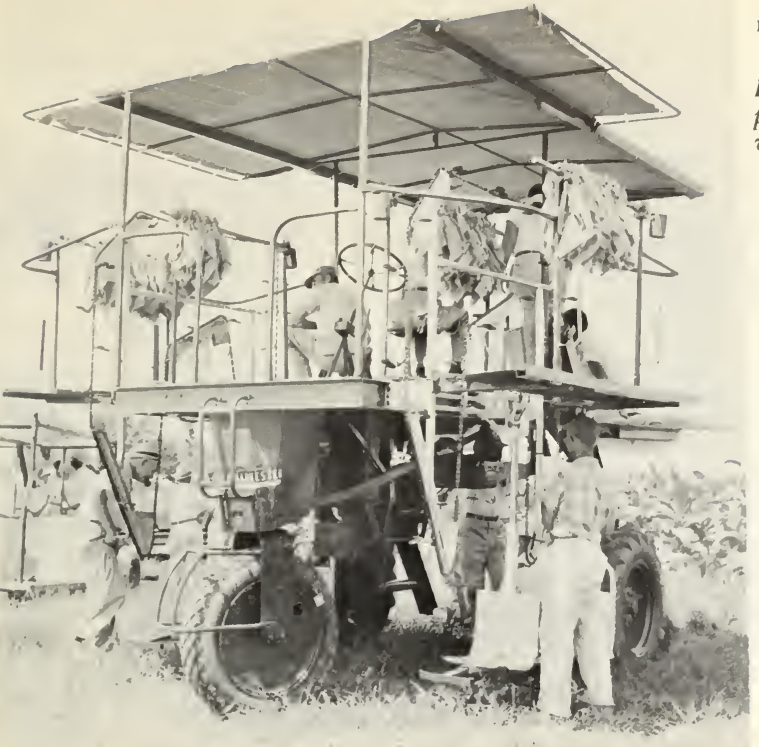

BN-39185

Figure 8.--A self-propelled

priming platform of a type

widely used in flue-cured areas.

Figure 9.--Experimental version

of mechanical barvestor devel-

oped for flue-cured tobacco.

BN-39242

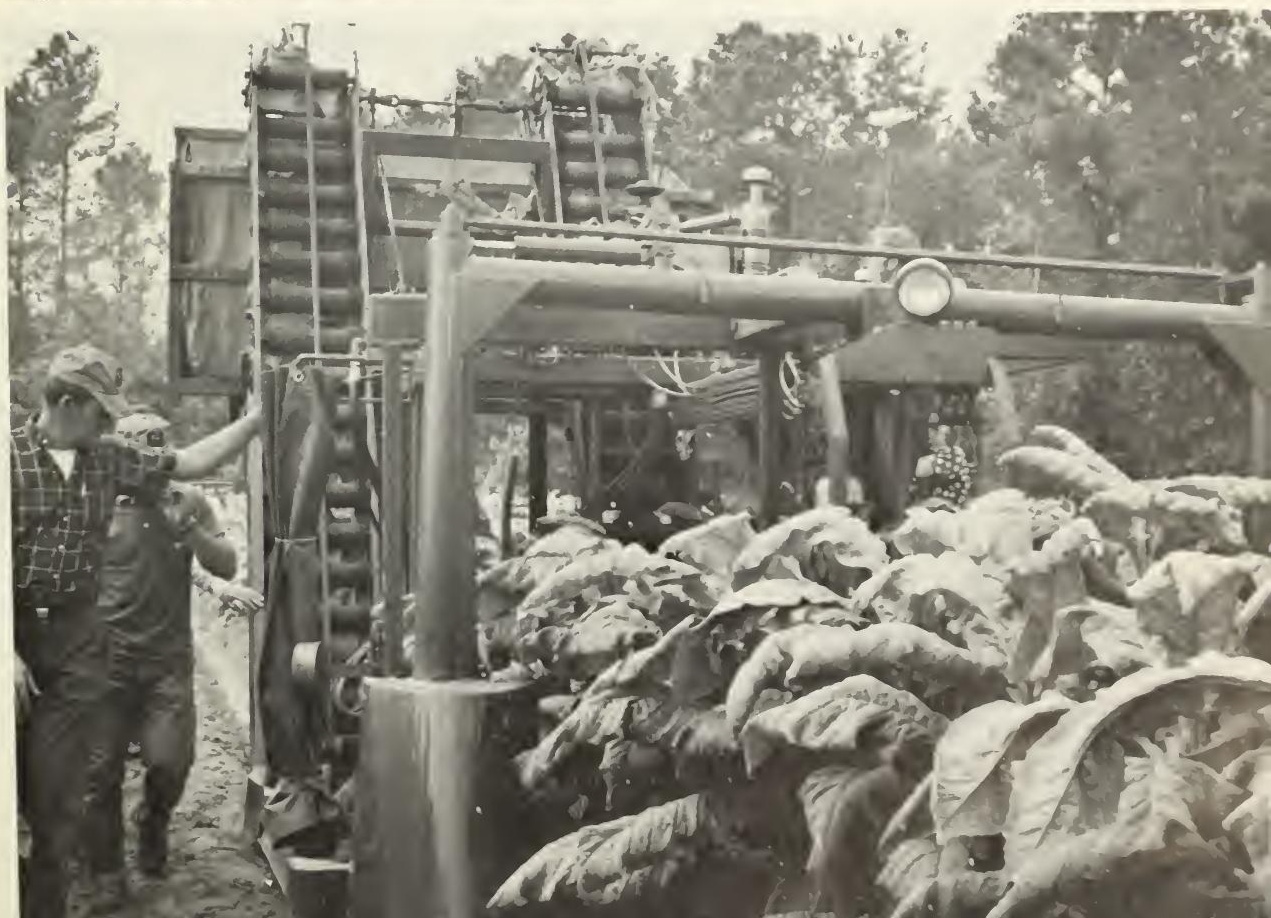


Figure 10.--Speared burley tobacco being loaded on wagons en route to the curing barns.

Figure 11.--This "tying machine" uses twine to secure flue-cured leaves to sticks for banging in the curing barns.

ST4064-17

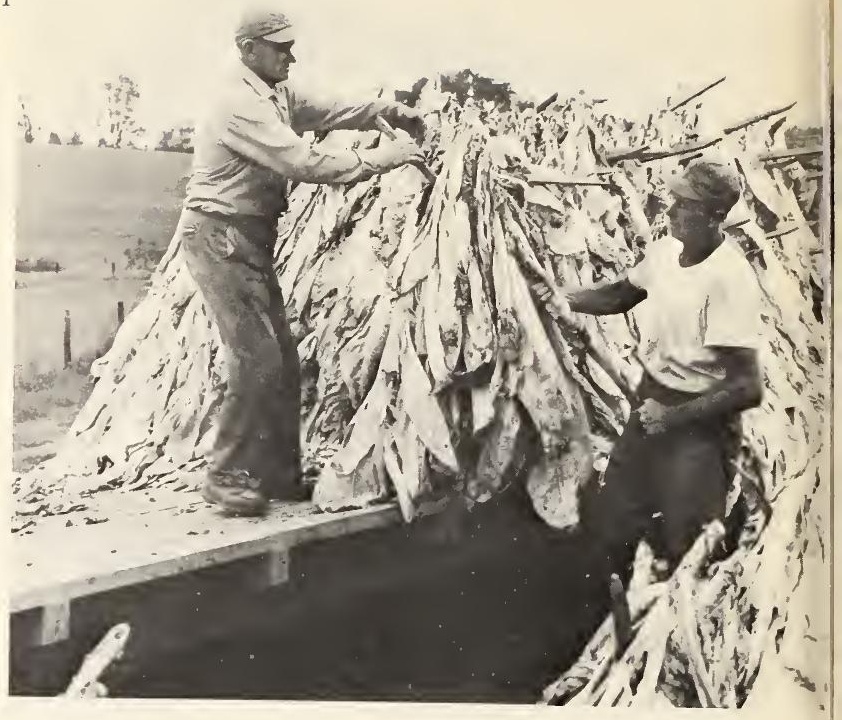

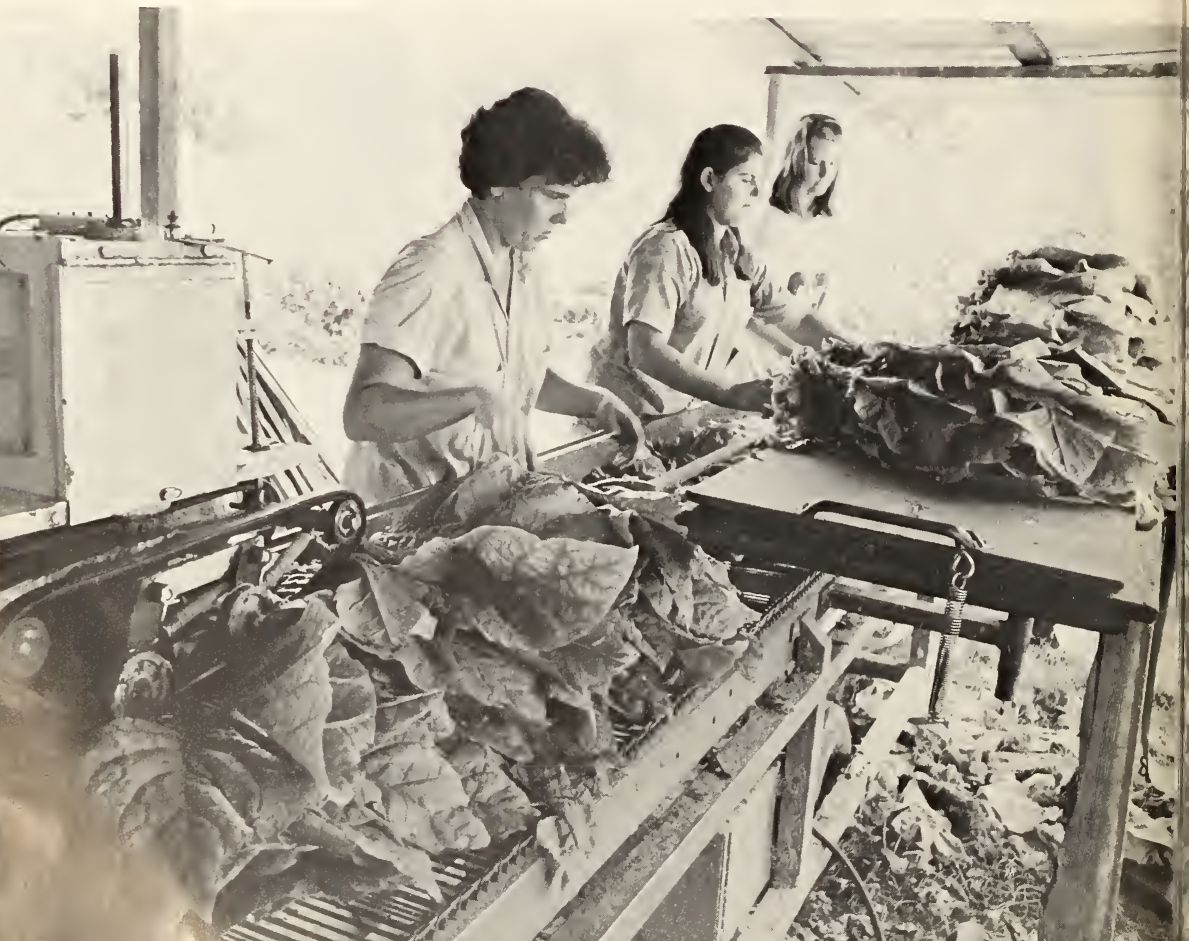


Figure 12.--Priming Georgia-Florida shade tobacco.

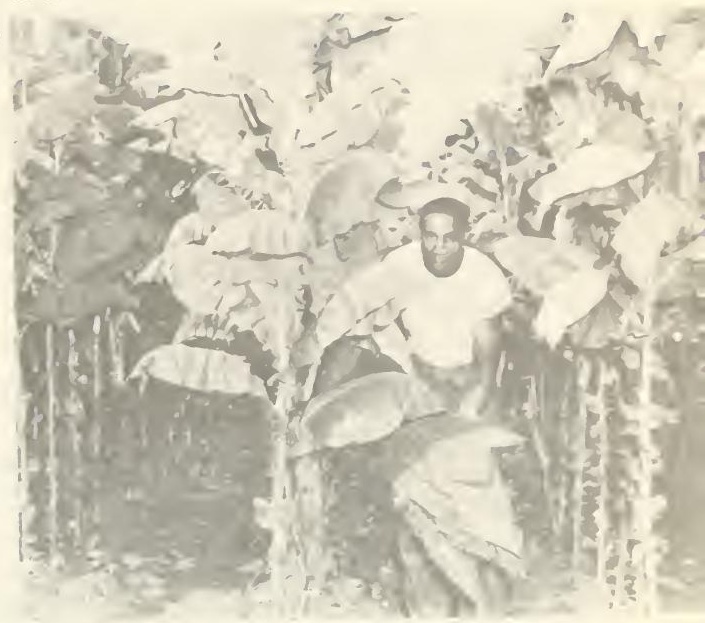

Figure 13.--Cutting the stalks of ripe burley tobacco.

BN-165+6 A.

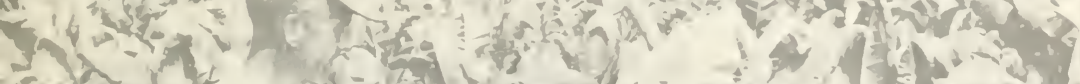

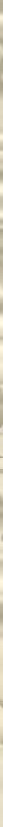


Flue-cured leaves are either attached to wooden sticks for conventional curing barns or placed in metal racks for the newer type of bulk curing barns. String is used to secure the leaves onto 4-1/2 foot wooden sticks. This is still largely done by hand but mechanical stitching machines are rapidly assuming this task. (fig.11).

Cigar wrapper leaves must be handled with care. They are strung onto 4-1/2 foot sticks by attaching a string at one end and running a threaded needle through the base of the leaves (arranged in pairs, back to back and front to front) for the length of the stick (about 15 to 22 pairs), and fastening it at the other end. In the Puerto Rican type, no sticks are used. The string is sewn through the butt of each leaf (about 40 to 50 leaves to a string) and tied to the tier poles.

(2) Stalk-cutting. Burley, Maryland, and fire- and dark air-cured, and most cigar leaf tobaccos are harvested by the stalk-cutting method. (fig.). (In some areas, particularly burley, farmers may prime the matured lower leaves, so that cutting of the stalks may be delayed until the plant is fully mature.) The entire stalk is cut close to the ground with a special type of hatchet resembling a tomahawk. Usually all plants in the field are harvested at the same time, but some less mature areas may be left and cut later. After being cut, the stalks are speared onto sticks--4-1/2 feet long (5 or 6 plants to the stick), and left in the field a day or so and allowed to wilt, so they will lose water and not break in handling (fig. 13 ).

The density of the tobacco on the sticks (or the string, in the case of Puerto Rican) is an important factor in the curing process, as satisfactory curing is made difficult by crowding. Care is taken that space is left between the plants (or leaves) for proper circulation of air. The tobacco is now ready for hanging in the curing barns.

Along with chemical changes that take place during the curing process, there is also a loss in weight from evaporation of a large quantity of the water contained in the leaf when it is harvested. Fresh leaf, as it goes into the curing barn, usually contains about 85 percent water, which is reduced to about 15 percent in curing. Therefore, about 5,666 pounds of green leaf will be required to yield 1,000 pounds of cured leaf, and two tons of water will be lost in the curing process.

\section{CURING}

There are three basic methods of curing tobacco:

(1) air-curing, in which the tobacco is primarily cured under natural weather conditions, but heat may be used to some extent;

(2) flue-curing, in which the tobacco is cured by heated air at gradually increasing temperatures, but must not be subjected to smoke or odors;

(3) fire-curing, in which the tobacco is mostly cured with wood fires and the smoke comes in contact with the leaf. 
The following outline shows harvesting and curing methods for each kind of tobacco:

\begin{tabular}{|c|c|c|c|c|c|c|}
\hline \multirow[b]{2}{*}{ Kind } & \multirow[b]{2}{*}{ Type } & \multicolumn{2}{|c|}{ Harvesting method } & \multicolumn{3}{|c|}{ Curing method } \\
\hline & & Priming & Stalk-cutting & Flue & Fire & Air \\
\hline Flue-cured & $11-14$ & $x$ & & $x$ & & \\
\hline Fire-cured & $21-23$ & & $x$ & & $x$ & \\
\hline Burley & 31 & & $x$ & & & $x$ \\
\hline Yaryl and & 32 & & $x$ & & & $x$ \\
\hline Dark air-cured & $35-37$ & & $x$ & & & $x$ \\
\hline Cigar filler & $41-44$ & & $x$ & & & $x$ \\
\hline Cigar filler & 46 & $x$ & & & & $x$ \\
\hline Cigar binder & $51-55$ & & $x$ & & & $x$ \\
\hline Cigar wrapper & $61-62$ & $x$ & & & & $x$ \\
\hline Perique & 72 & & $x$ & & & $x$ \\
\hline
\end{tabular}

The curing processes and barns are described separately below.

Air-curing (burley, Maryland, dark air-cured, and cigar types)

Type of barn. Barns used for air-curing tobacco are 30 to 40 feet widt and vary in length up to 300 feet. Boards on the outside of the barn may be either vertical or horizontal. About every third board is hung on hinges and functions as a ventilator. Horizontal bottom ventilators are also provided along the entire length of the sides of the barn to admit air near the ground, and many barns have additional ventilators along the peak of the roof (figs. $14,16, \& 18$ ).

The barn usually has driveways and doors large enough to allow a wagon or truck to pass through easily. The interior consists of a framework of poles for supporting the laths on which the tobacco has been placed (fig. 15). The spaces between the poles are called tiers. Barns are built 3 to 4 tiers high. The first tier of poles is at least 9 feet from the ground, so that the tobacco on the bottom tier clears the ground by at least 3 feet. The other tiers are 4 or 5 feet apart. The tier poles are usually about 16 feet long, and strong enough to carry at least 800 pounds.

Air-curing operation. All air-cured tobaccos are harvested by stalk-cutting, except shade-grown wrapper and Puerto Rican filler, which are harvested by priming. The surplus food supply that the plant accumulates before harvesting helps it to live several days after being cut. When this is exhausted, the leaf dies and is then nearly cured. We might say, therefore, that aircuring tobacco is forcing the leaves to go through a process of gradual starvation under proper conditions.

The time required for completely curing stalk-cut tobacco varies, depending on weather conditions, from 5 to 8 weeks for the cigar types, and from 4 to 6 weeks for burley, Maryland, and the dark air-cured types. 
When cured, the color of burley is a tan to reddish brown, as compared with the deeper brown of cigar leaf. Although the stalks may still be quite green, the cure is finished when the midrib (central vein of the leaf) is dried out and free of sap. The amount of supplementary heat required during the curing period varies considerably with the weather, and is particularly important under cold or excessively wet conditions.

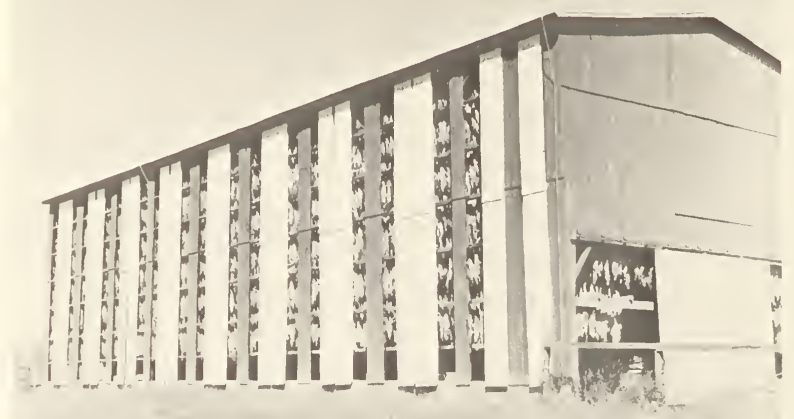

BN- 16547

Figure 14.-- Exterior view of burley curing barn.

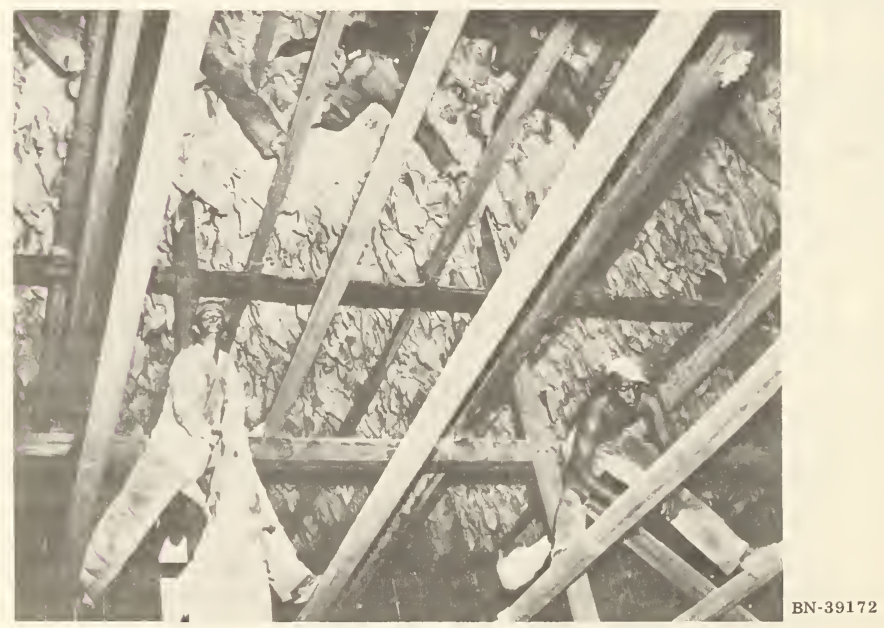

Figure 15.-- Speared burley being placed on the tier poles. 


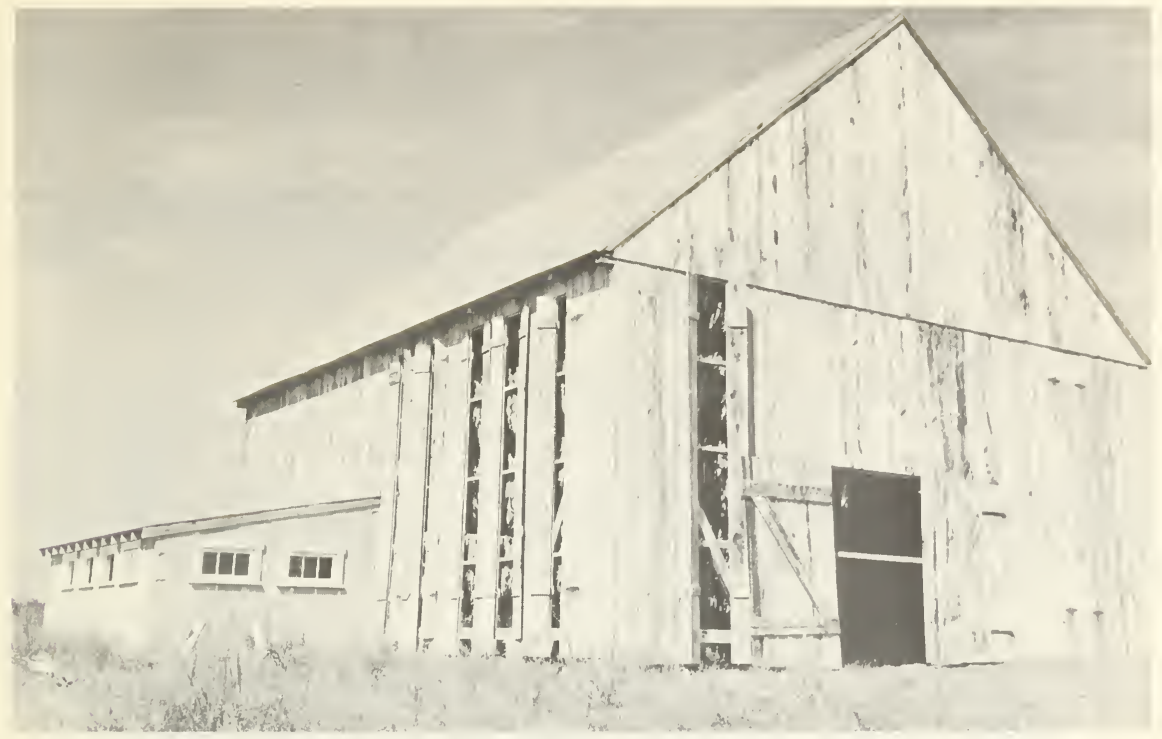

Figure 16.--Maryland curing barn.

The air-curing of primed shade-grown cigar wrapper and Puerto Rican filler usually takes from 4 to 6 weeks. Supplementary heat is almost always used $\overline{\text { in }}$ curing shade tobacco, essentially to protect the product, and to maintain the temperature at a favorable level rather than to elevate it. A small amount of cigar wrapper is put through a rapid cure under high heat to produce a leaf of greenish color. This is known as fire-cured or candela-cured leaf.

When fully cured, the leaf is too dry and brittle to be handled without serious damage. However, tobacco leaves easily absorb moisture from the air and will readily absorb 20 percent or more under warm, humid conditions. Therefore, the tobacco is not taken down from the tiers until after damp weather has made the leaves soft or pliable enough to be handled without breaking Such weather is often spoken of as a "tobacco season," and the leaf in this condition is said to be "in case" or "in order."

In the case of stalk-cut tobacco, as the plants are taken from the sticks they are usually arranged in piles or "bulks" in such a way that the tobacco will not dry out for several days. The leaves are stripped from the stalks as soon as possible.

In the auction market areas, as the leaves are removed from the stalks they are sorted into several grades, according to stalk position, quality, color, and size and tied into "hands." The tobacco is then bulked down until time for delivery to the auction market. 
Stalk-cut cigar tobaccos are packed in farm bales or bundles as the leaves are stripped. Most cigar tobacco is now sold unsorted, except that very inferior qualities are thrown out as the leaves are stripped from the stalk. Specially constructed box presses are used for packing. After placing four heavy strings in the box, it is lined with heavy manila paper which is used to wrap the bundle. The leaves are laid with the tips overlapping, and the butts of the leaves to the outside of the bundles on each end. The leaves are not tied in "hands" by the growers, as in the auction market areas. When the box is full, the leaves are pressed down, the paper folded over, and the strings tied. The tobacco is ready for delivery to a buyer. The weight of a farm bale ranges from 40 to 60 pounds.

After the primed shade-grown tobacco is completely cured, the sticks of leaves are taken down and placed in temporary bulks with the sticks to the outside. The tobacco is then removed from the sticks by detaching the string at each end and tying the ends together to form a hand. The hands are packed in wooden boxes for delivery to the packing house. After curing, the primed Puerto Rican tobacco is prepared for delivery by detaching the strings from the tier poles and tying them together around the rolled up leaves to form hands.

Figure 17.--Connecticut Valley cigar binder tobacco banging in curing barn.

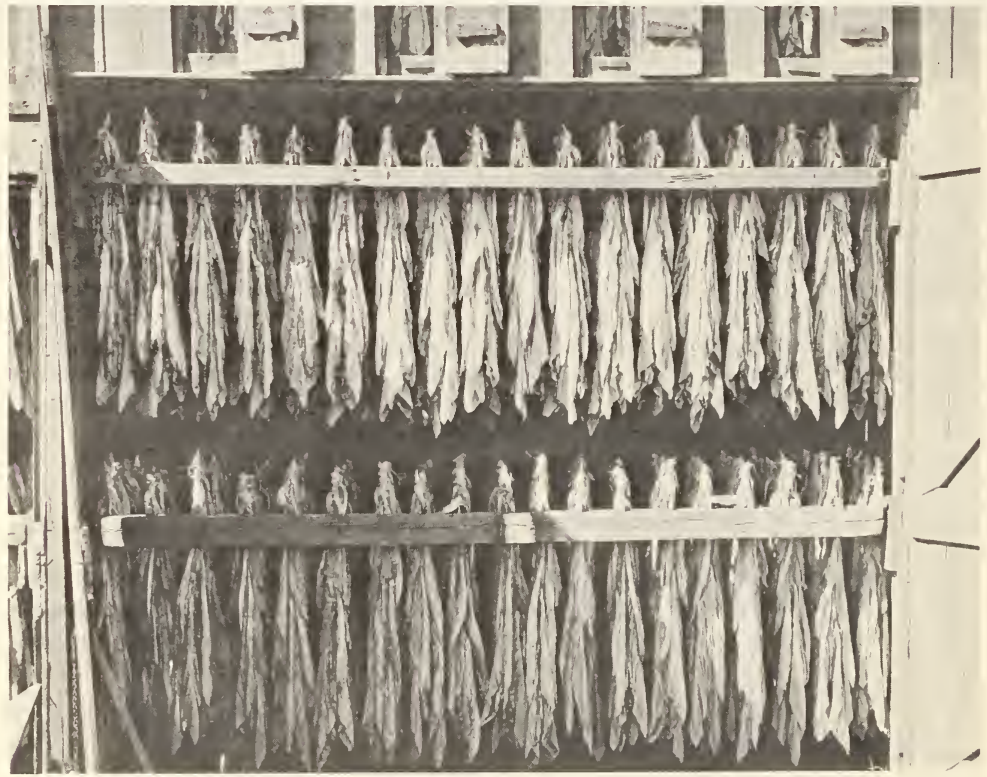




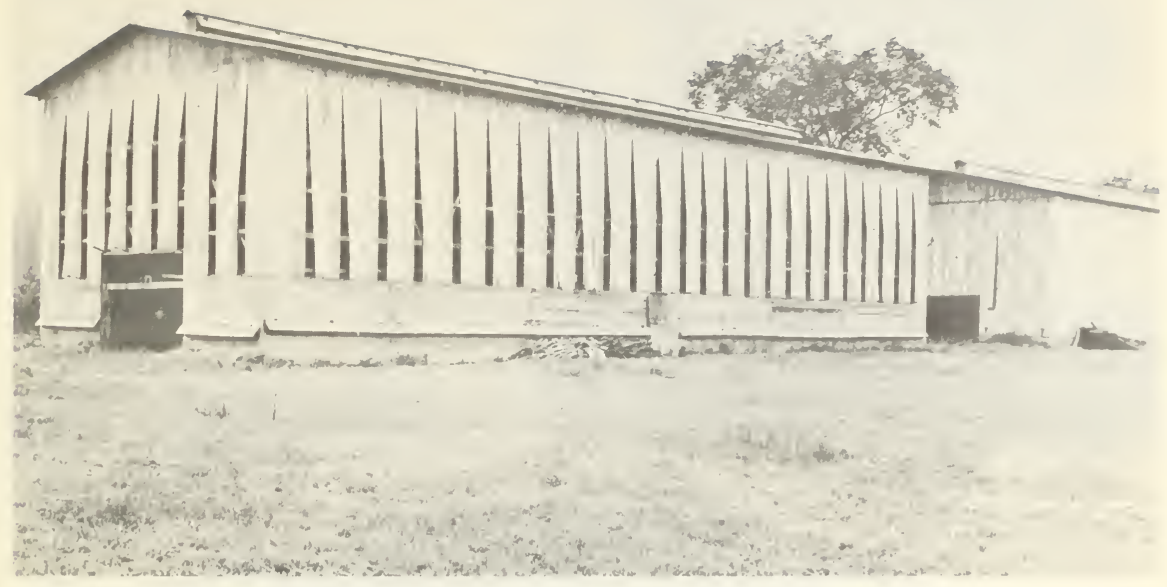

Figure 18.--Curing barn for Connecticut cigar binder.

Flue-curing (flue-cured types)

Type of barn. Two types of barns are used for curing flue-cured tobacco, the conventional barns and the more recently developed bulk curers. The conventional barns are small and simply built (figs.21 and 22). They are usually square, with inside measurements 16,20 , or 24 feet, and contain tier poles spaced about 4 feet apart. The vertical spacing is about 26 inches. The barns have solid walls and ventilation is provided at the top and around the bottom.

Formerly, all flue-curing barns were heated with wood-fired furnaces of stone or brick built partly outside the barn at ground level. Metal flues from the furnace extended around the floor of the barn radiating heat for curing the tobacco. The next development was oil-fired furnaces to replace wood. Most conventional barns now use oil-burning heaters or open-flame gas heaters located inside the barn.

Flue-cured growers are converting to the "bulk curing" system. The curing barn is a specially constructed building (fig. 20) with built-in devices for more precise temperature, humidity, and ventilation control. The curing procedure is the same as in the old barns except that fans are used to force the heated air through the tobacco which is very closely spaced on special meta ${ }^{2}$ racks instead of sticks. As mechanical harvesting machines are perfected, bulk curers will replace the conventional barns. 


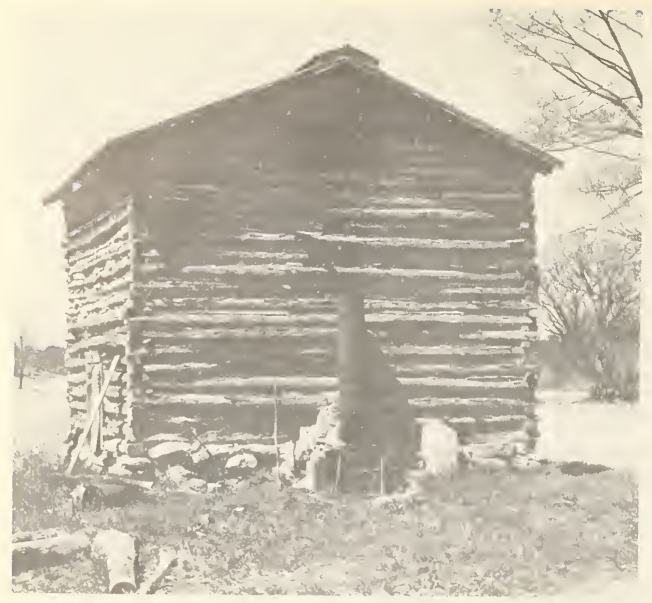

BN-39180

Figure 19.--The old flue-curing barns bad wood burning fire boxes on the outside.

Figure 20.--A modern barn for bulk curing flue-cured tobacco.

BN-39187

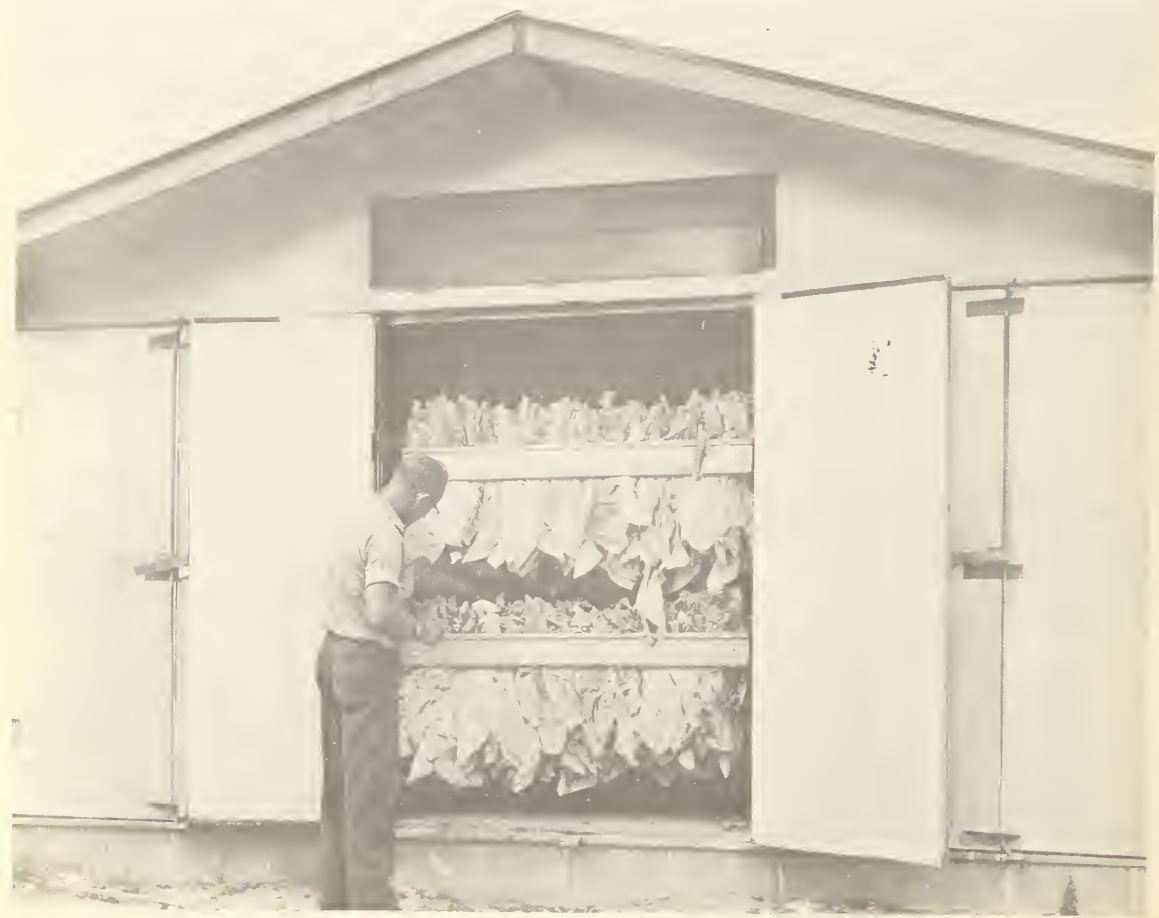


Flue-curing operation. When priming begins, curing barns are completely filled each day to insure uniformity in the curing. Heat is applied with attention to the gradual changes in the leaf, particularly to the changes in color and moisture content. Curing may be considered to take place in three stages: (1) Yellowing, (2) drying of the leaf, and (3) drying of the stem. (1) In the yellowing stage, the heat is maintained at around $90^{\circ}$ to $100^{\circ}$, for 24 to 40 hours under average conditions; (2) it is then moved up fairly rapidly to $135^{\circ}$ to $140^{\circ}$ to dry the leaf and fix the color, which takes from 30 to 36 hours; (3) and then it is gradually raised to $160^{\circ}$ and maintained at this level until the stems are thoroughly dry. Careful watch is kept through out the whole curing process, which is completed in 4 to 6 days.

When the curing is completed, the tobacco is quite dry and brittle. In order not to shatter the leaves it must be brought in "case" (see page 21). If the leaf can be folded in the hand without breaking the stem, it is in proper condition to be taken down without injury.

Sometime prior to delivery to the auction market, the tobacco is sorted into different lots or grades. As a rule, the different primings are handled separately and only a few grades are made of each. Care is taken to remove all the strings by which the leaves were attached to the sticks with the conventional curing method. Metal racks hold the tobacco for bulk curers and no strings are used.

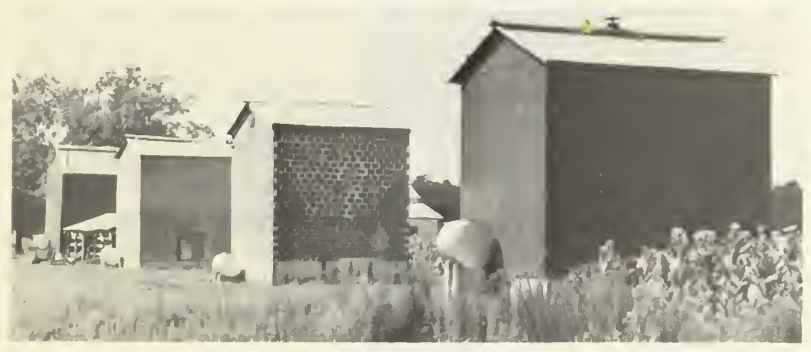

Figures 21 and 22.--Conientional flue-curing barns.

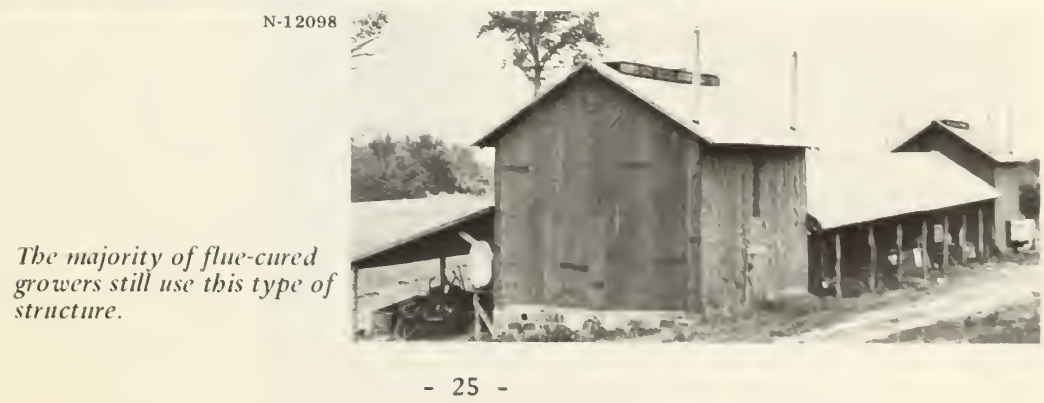


The sorted lots of leaves are placed on burlap sheets and delivered to market. Prior to 1965 only Georgia and Florida growers sold tobacco in this manner, while Carolina and Virginia farmers tied their tobacco into "hands" or small bundles. At the present time only a minute quantity of flue-cured is sold in tied form.

\section{Fire-curing (fire-cured types)}

Type of barn. The old type of barn used for fire-curing was built of logs and the cracks daubed with mud. These barns were small, but generally high enough for 5 sets of tier poles. Modern barns (fig. 23) are frame buildings, much larger, with passageways through which a loaded wagon or truck may be driven directly beneath the tier poles.

Fire-curing operation. Fire-cured tobacco is harvested by stalk-cutting . Usually no heat is required during the first stage of the curing, in which the leaf begins to yellow. After the tobacco has been in the barn from 3 to 5 days, slow fires of hardwood or hardwood sawdust are started on the floor (fig. 24) and temperatures are kept low until the leaf is completely yellowed. Temperatures are then increased and the higher heat maintained until the leaf tissue is pretty well dried out. Altogether, the fires are kept burning for 3 to 10 days in some sections, and 10 to 40 days in others.

The main objective in fire-curing is to give the leaf a special smoky taste and aroma, which is accomplished through contact with the smoke from the open fires. Care is taken to regulate the proper combination of heat, humidity, and ventilation in order to prevent injury to the leaf, and to protect it against mold and discoloration through scalding. Caution is also used in guarding against the danger of barn fires, which can result in the loss of entire crops.

When the plants are thoroughly cured and have absorbed enough moisture to make them pliable, they are removed from the sticks and the leaves removed and sorted. Three principal grades are usually made, mainly on the basis of body and the position of the leaf on the stalk, and these may be further subdivided on the basis of size and color. The tobacco is then tied into "hands" or bundles for marketing.

\section{Curing Perique tobacco}

The curing process for Perique is unique. The entire plant is cut, a nail is driven at an angle through the butt of the stalk, and the plant is hung from wires stretched across the curing barn. After 8 to 14 days, when the leaves have dried and turned brown, they are stripped from the stalks, formed into small twists, and packed in casks under great pressure until they turn black. Every few days during the first month, the tobacco is taken out, loosened, and put back again under the pressure. The process gives Perique its characteristic aroma. It is cured wholly in its own juice, without any other ingredients. It is allowed to ferment for about nine months, under this pressure, and is then ready for market. 
Figure 23.--Fire-cured tobacco after curing is completed. Note remuants of fires on floor.

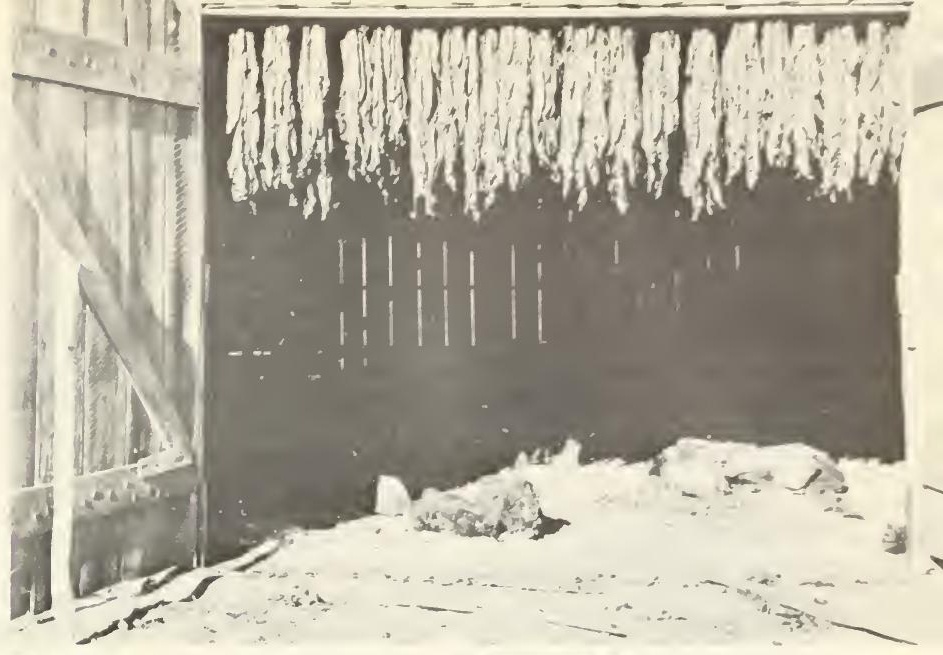

Figure 24.--Fire-cured curiulg barm. BN-39181

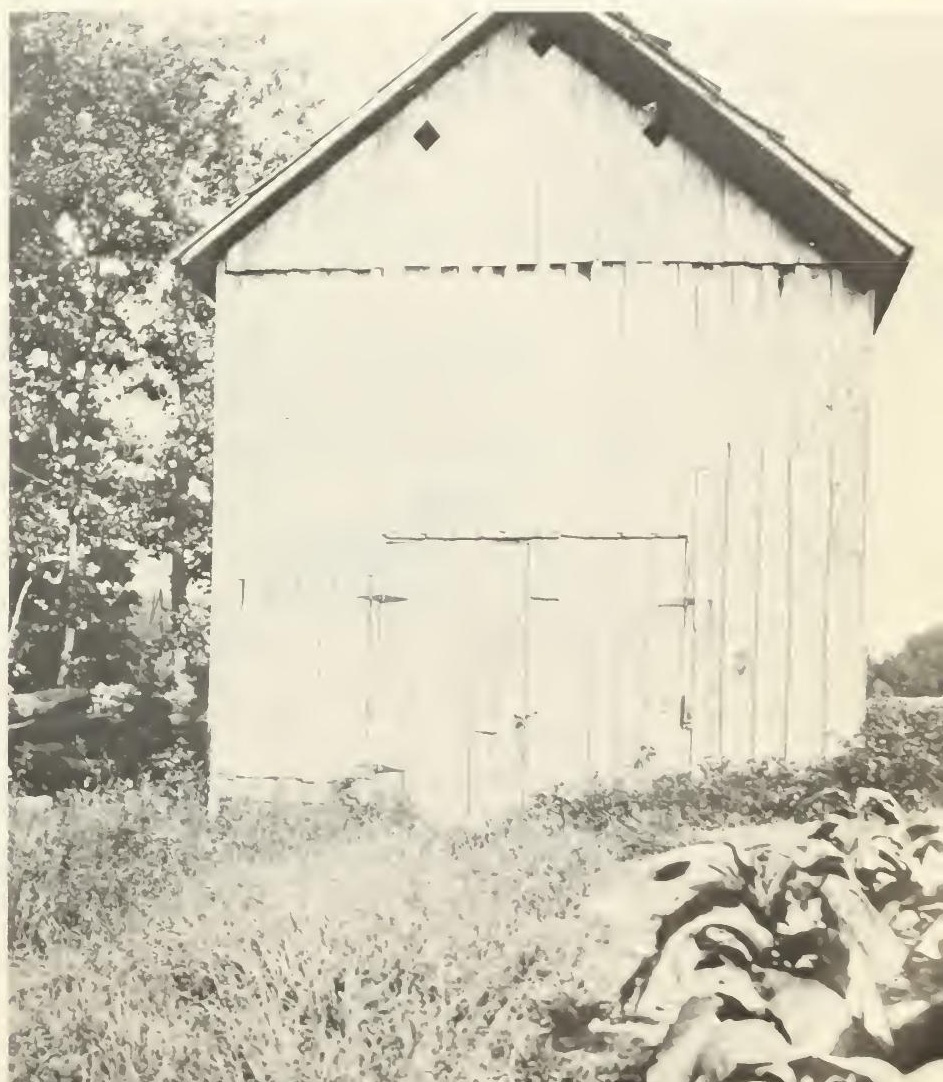


Around 95 percent of the tobacco grown in the United States is marketed by the "loose leaf" auction method. The remaining 5 percent, made up principally of cigar-leaf tobacco, is sold either directly on the farms or through farmer-owed cooperatives. A small quantity is sold in hogsheads.

The modern version of the loose-leaf auction system first appeared in Danville, Va., shortly before the Civil War. Following the conflict, the system came to be widely accepted throughout the rapidly-expanding flue-cured belt in the North Carolina and Virginia areas. Auction marketing was introduced in the Kentucky and Tennessee areas at Clarksville, Tenn., in 1901.

\section{AUCTION METHOD OF SELLING}

Growers deliver their tobacco to the auction warehouse of their choice, where it is sold to the highest bidder. The bidders are buyers for manufacturers, dealers, and exporters, as well as independent dealers or speculators. The auction system is of vast proportions, providing facilities for handling nearly 2 billion pounds of tobacco annually, mostly during the period from August through February.

The length and period of the marketing season varies for the different types of tobaccos, and, to some extent, from year to year. The selling begins when the Georgia and Florida flue-cured markets open toward the end of July of the year of production, and ends when sales in Maryland are completed in the latter part of June of the year following production. The season is so staggered that it is possible to find an auction sale in progress in some area almost any time during the year. The following chart shows the approximate marketing periods for the types sold at auction:

\section{APPROXIMATE PERIODS OF TOBACCO AUCTION MARKETING SEASONS}

\begin{tabular}{|c|c|c|c|c|c|c|c|c|c|c|c|c|c|}
\hline CLASS \& TYPE & JUL. & AUG. & SEPT. & OCT. & Nov. & DEC. & JAN. & FEB. & MAR. & APR. & MAY & JUNE & JUL. \\
\hline \multicolumn{14}{|l|}{ Flue-cured: } \\
\hline \multicolumn{14}{|l|}{14} \\
\hline \multicolumn{14}{|l|}{13} \\
\hline \multicolumn{14}{|l|}{12} \\
\hline \multicolumn{14}{|l|}{ II (b) } \\
\hline \multicolumn{14}{|l|}{$11(a)$} \\
\hline \multicolumn{14}{|l|}{ Burley: } \\
\hline \multicolumn{14}{|l|}{31} \\
\hline \multicolumn{14}{|l|}{ Fire-cured: } \\
\hline \multicolumn{14}{|c|}{-} \\
\hline \multicolumn{14}{|l|}{22} \\
\hline \multicolumn{14}{|l|}{23} \\
\hline \multicolumn{14}{|l|}{ Dark air-cured: } \\
\hline \multicolumn{14}{|l|}{35} \\
\hline \multicolumn{14}{|l|}{36} \\
\hline \multicolumn{14}{|l|}{37} \\
\hline Maryland: & & & & & & & & & & & & $*$ & \\
\hline 32 & & & & & & & & & & E & $\therefore$ & $+\ldots$ & \\
\hline
\end{tabular}


Markets are situated in towns or cities in growing areas where one or more warehouses sell tobacco at auction. There are 898 warehouses at the 176 auction markets in the United States (1971). The largest market has 28 warehouses, and some of the smaller markets have only one. They are located in 12 states and sell 13 types of tobacco, as shown in the following table.

Tobacco auction markets and warehouses, by States and classes in the United States, 1971-72 season

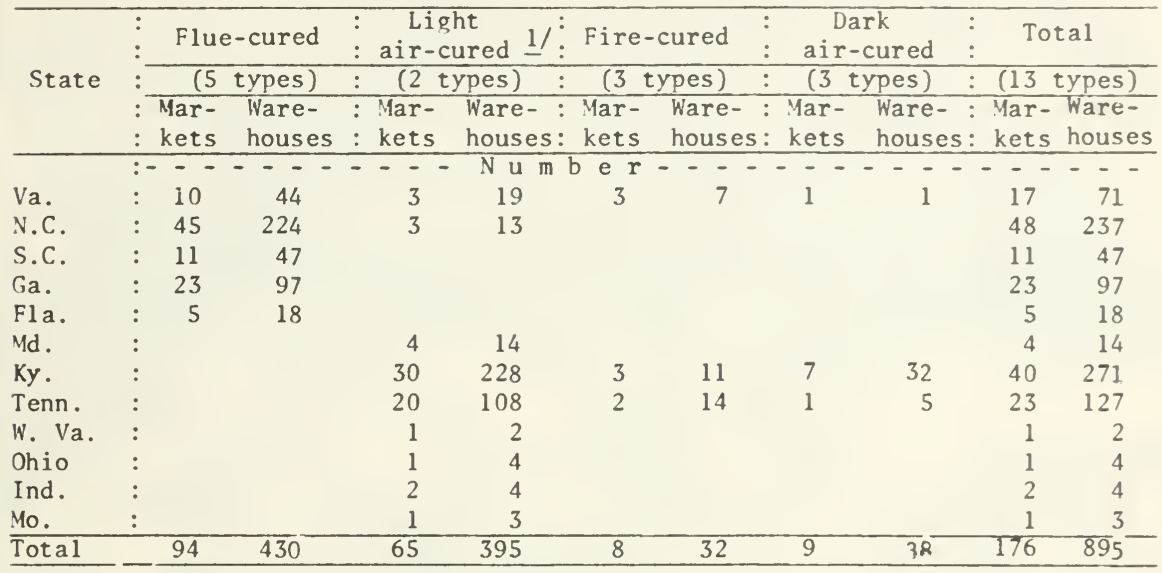

1/ Maryland type, Maryland only; Burley, all other States.

Warehouse construction. The auction warehouse is designed for the purpose of providing proper and uniform marketing conditions for the display and sale of farmers' tobacco. An important factor in warehouse construction is the provision for lighting. U.S. Department of Agriculture regulations require that the tobacco be classed and graded under "proper light for correct determination of grade or other characteristics of tobacco." Natural daylight has always been regarded as the proper source of lighting, and the type of building that provides such natural lighting is so distinctive that an auction warehouse can be instantly recognized. The low roof, studded with sky-lights, identifies it at once. Artificial lights have been develoned, which are satisfactory for grading and classing, and it is possible that such lighting may replace natural lighting to some extent in the future, particularly wen new warehouses are being built.

Some of the largest buildings have an area as large as seven acres and can disnlay as many as 7,000 baskets of tobacco at one time. However, the average warehouse is not this large. The floor is made of heavy planking, concrete, or asphalt with a driveway down one or both sides, and, in some of the larger buildings, also down the middle. These driveways are usually below the floor level for the convenience of farmers in unloading the tobacco onto the floor, and buyers in loading it out after the sale. 


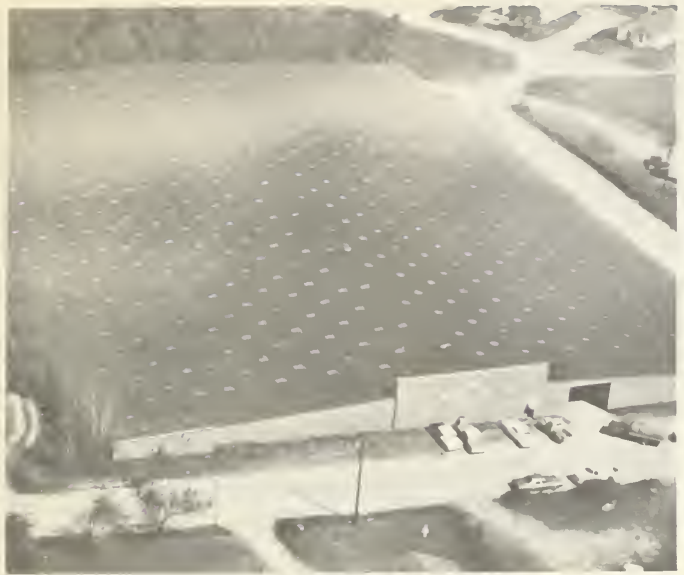

BN-39241

Figure 26.--Aerial view of typical flue-cured auction warebouse showing skylights.

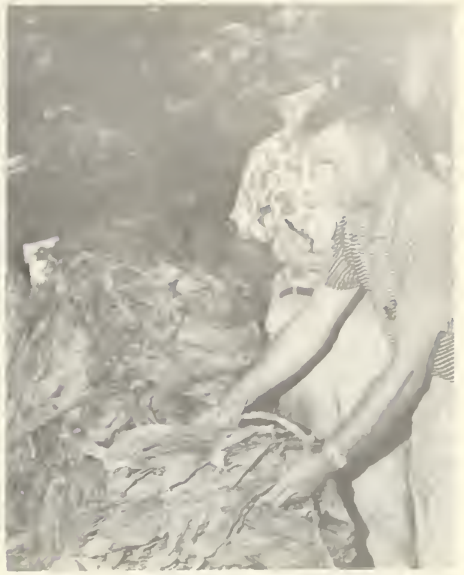

BN-18029

Figure 27.--Federal tobacco inspectors examining flue-cured tobacco.

Before the sale. The majority of farmers transport their tobacco to the warehouse in small trucks. Delivery may be several hours or even days before the sale. Many warehouses schedule or "book" deliveries by growers for sale on specified days. Flue-cured tobacco is delivered and displayed for sale in burlap sheets weighing up to 200 pounds. All other types use the traditional wooden "basket" about 40 inches square, furnished by the warehouse. The individual "hands" of tobacco are arranged on the baskets to make distinctive displays. Weights of the baskets vary greatly, depending on type, with the largest exceeding 600 pounds. In some markets, warehouse employees supervise the packing of tobacco onto the baskets. The baskets or sheets are weighed and assigned a ticket containing several carbons. This ticket shows the grower's name, basket serial number, warehouse name, and weight in pounds. Spaces are also provided for the Government grademark, buyer's name and grademark, and selling prices. After weighing, the sheets or baskets are moved on the warehouse floor and arranged in rows in preparation for the sale.

Government inspection and market news services on auction markets. Short$1 y$ before the sale, a Federal inspector examines each lot of tobacco and grades it according to official United States standards. He enters the grade, date, and his initials on the sales ticket, which becomes the certificate of grade for that lot of tobacco. After the sale, data on grades and prices are collected from these tickets to form the basis for published market news reports. Current price reports are available to growers on the auction floors.

Inspection and market news services authorized by The Tobacco Inspection Act are now in effect on all auction markets. The Act provides for free and mandatory inspection on markets designated by the Secretary of Agriculture, after favorable referenda of growers selling on such markets. Government grading and market news services aid the farmer by accurately describing his tobacco and enabling him to determine whether his bid price is a fair one. 


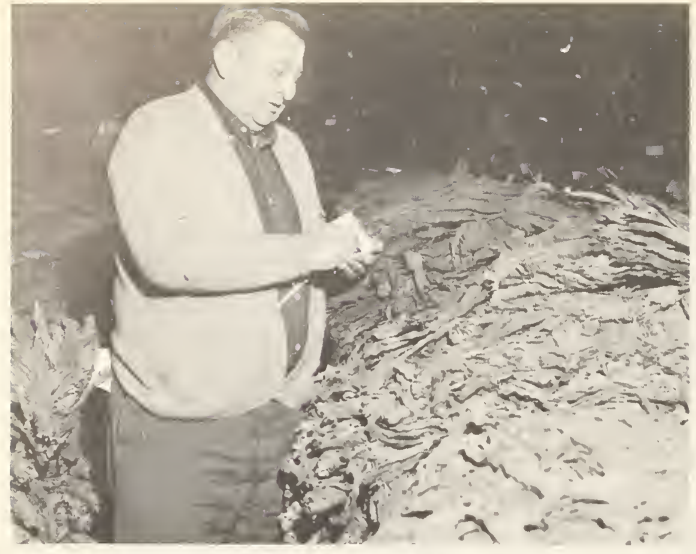

Figure 28.--A Federalinspector grading Maryland tobacco in an auction warebouse.

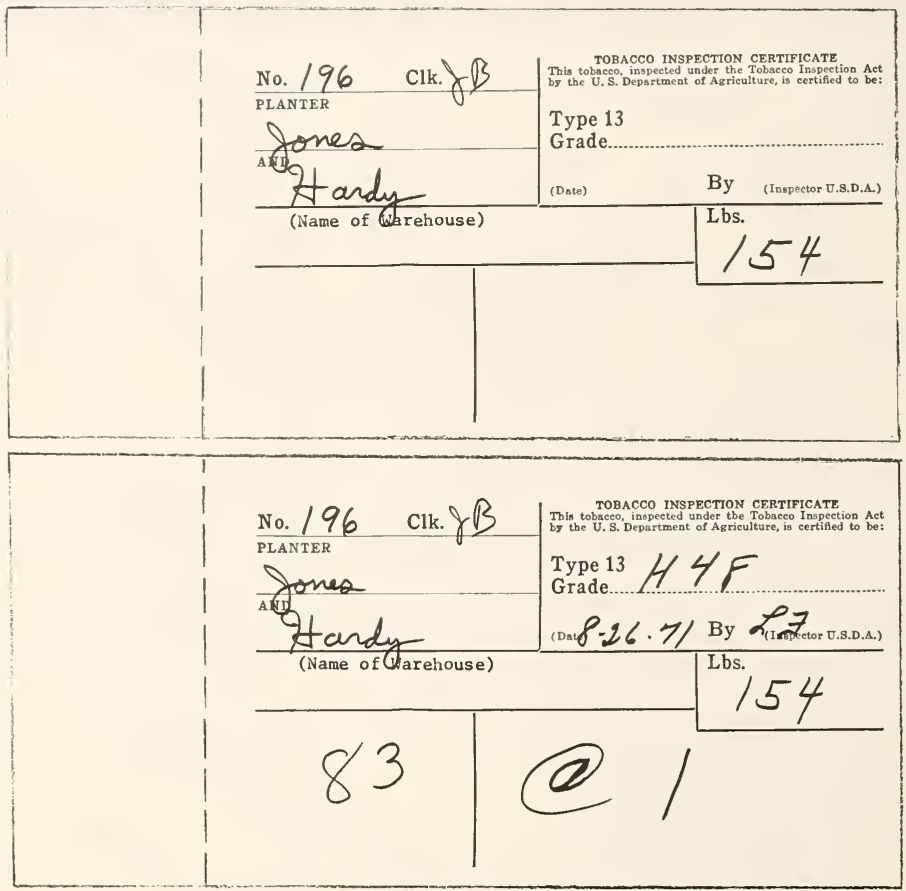

The combination Inspection Certificate and sales ticket before and after auction sale. 


\section{Tobacco Market Prices}

MIDDLE BELT FLUE-CURED - TYPE 11 (b)

U.S. DEPARTMENT OF AGRICULTURE - AGRICULTURAL MARKETING SERVICE - TOBACCO DIVISION North Carolina Department of Agriculture Cooperating

Gross Sales: Tuesday - 4,185,462 pounds - average $\$ 78.32$

Season - 99,936,495 pounds - average $\$ 85.70$

Auction b1d averages and support prices by U. 8. Grades - Wednesday, October 25,1972 U. 8.
GRADE AVG. SUP. GRADE AVG. SUP. GRADE AVG. SUP. GRADE AVG. SUP. GRADE AVG. SUP.

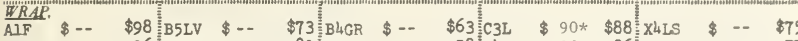

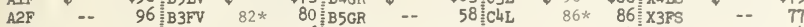

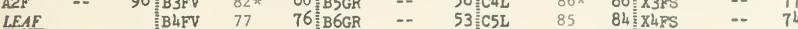

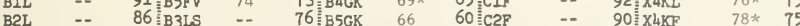

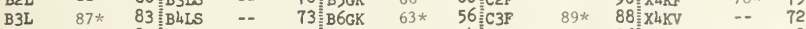

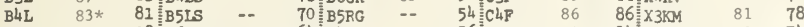

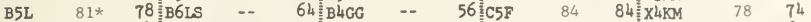

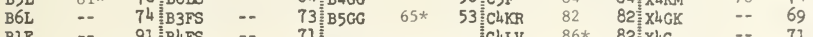

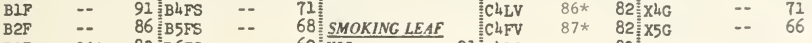

B3F 86* 83 86 BFS -- 62 61 HIL

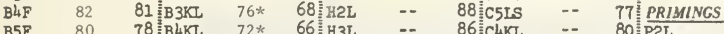

B5F 8078 BLKL $72 \% 66$ H3L

B6F 75* 74

BLF -- $90 \mathrm{~B} 6 \mathrm{KL} \quad-\quad 58 \mathrm{H} 5 \mathrm{~L} \quad 85 * \quad 81 \mathrm{~F} 4 \mathrm{KM}$

B2FR -- 85 B3KF $72 \quad 67 \mathrm{H}$ (

B3FR -- 82 B $4 \mathrm{KF} \quad 70 \quad 65$ HIF ‥

B4FR $83 * 79$ B5KF 6962 H2F

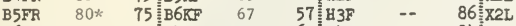

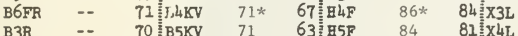

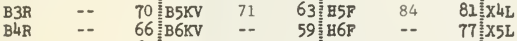

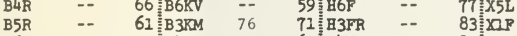

B6R -- $\quad 57$ B $4 \mathrm{KM} \quad 74 \quad 69$ H4FR

B3K 79* 76 B5KM 73 66 -.

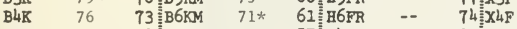

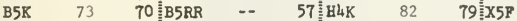

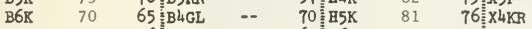

B3KR $82 * 76$ :

BLKR $80 \quad 73$ is6 GL

B5KR 76* 70 B4GF

$\begin{array}{lll}\text { B } 3 L V & -. & 80 \\ \text { B } 4 L V & 78 * & 765 G F \\ \end{array}$

\begin{tabular}{|c|c|}
\hline & \\
\hline Groups & Qualities \\
\hline A.Wrappers & 1. Choice \\
\hline B.Leat & 2. Fine \\
\hline H.Smoking Leaf & 3.Good \\
\hline C.Cutters & 4.Far \\
\hline$x$ L Lugs & 5-Low \\
\hline P.Pfimings & 6Poor \\
\hline $\begin{array}{l}\text { N. Nondescript } \\
\text { SScrap }\end{array}$ & \\
\hline
\end{tabular}

-- $67 \mathrm{6T}$

-. 62

$72 * 69$ CUTTERS -. 6I C2L

80 P2L -- 83

80 P3L $80 * 80$

$81 \quad 80 \mathrm{PLL} \quad 77 \quad 77$

PSL 73* 72

$\begin{array}{lll}73 * & & 72\end{array}$

-- 88:P3F $81 * 80$

$87 * \quad 86 \mathrm{P} 4 \mathrm{~F} \quad 77 \quad 77$

$84 \quad 84$ P5P $73 \quad 72$

81 81:P4G -- 68

-- $77 \mathrm{P5G} \quad$.- 62

-- 88 .

88 * 86 NONDESCRIPT

$8464 \frac{1 \mathrm{NL}}{66} 64$

82 81NIXI 69*68

78 77)

80 T8EIR

$84 * \quad 80 \mathrm{~N}$ NGL

84 * 77NIGF

$81 * \quad 80$ NIGR

$79 * \quad 77$ NIGG $79 \div 12$

ANDARD GRADE MARKS FOR FLUE-CURED TOBACCO
Color Symbols
$70 * 65 \mathrm{CIL} \quad \mathrm{X}$

\begin{tabular}{|c|c|c|}
\hline Qualities & \multicolumn{2}{|c|}{ Color Symbols } \\
\hline Choice & L.Lemon & GL.Groen Lemon \\
\hline Fine & F. Orange & GF. Green Orange \\
\hline Good & FR-Orange Red & GR.Green Red \\
\hline Fair & R.Red & GK.Groen Variegated \\
\hline Low & K.Vanegated & GG-Gray Green \\
\hline Poor & KR-Variegated Scorched & KL.Vanegated Lemon \\
\hline & G-Green & KF. Vanegated Orange \\
\hline & LV.Lemon Greenish & KV Variegated Greenish \\
\hline & FV. Orange Greenish & KM. Variegatod Mixad \\
\hline
\end{tabular}

For example: B4F designates leat, fair quality, and orange color

*Latest average established.

Sample tobacco market price report.

Figure 30.--Market reporter releases information to news media.

BN 18023

Figure 31.--Grower obtains market news report at anction warehouse.
Figure 29.--Price recorder collects information during sale.

BN-39652
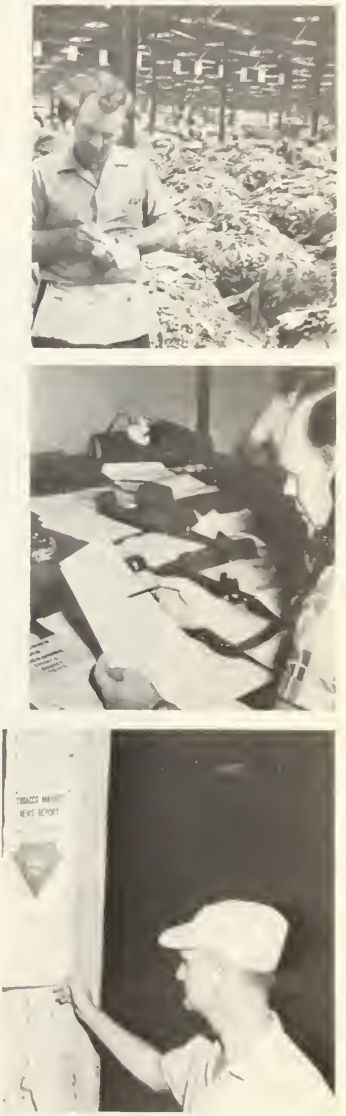
The auction sale. The auction sales group is made up of (1) the auctionneer, (2) the warehouseman or his representative, who calls an opening bid,(3) a corps of buyer representatives (usually 6 to 8 ), known as a "set of buyers," and (4) the warehouse clerk who follows and records the details of the sale such as buyer's name and grademark and the price bid onto the basket ticket. Usually, a number of growers and other spectators are observing the sale.

The starting bid is made by the warehouseman or his representative, and since it indicates the warehouseman's valuation of the tobacco, it has an important effect on following bids and on the price paid. The auctioneer calls out the starter's opening bid, receives other bids, and announces the selling price and buyer when the bidding is finished. Various quick signs are made by the buyers and accepted as bids by the auctioneer, and the auction sale moves along very rapidly. In the flue-cured district, the rate of sales is 500 lots per hour, and in burley, 360 baskets.

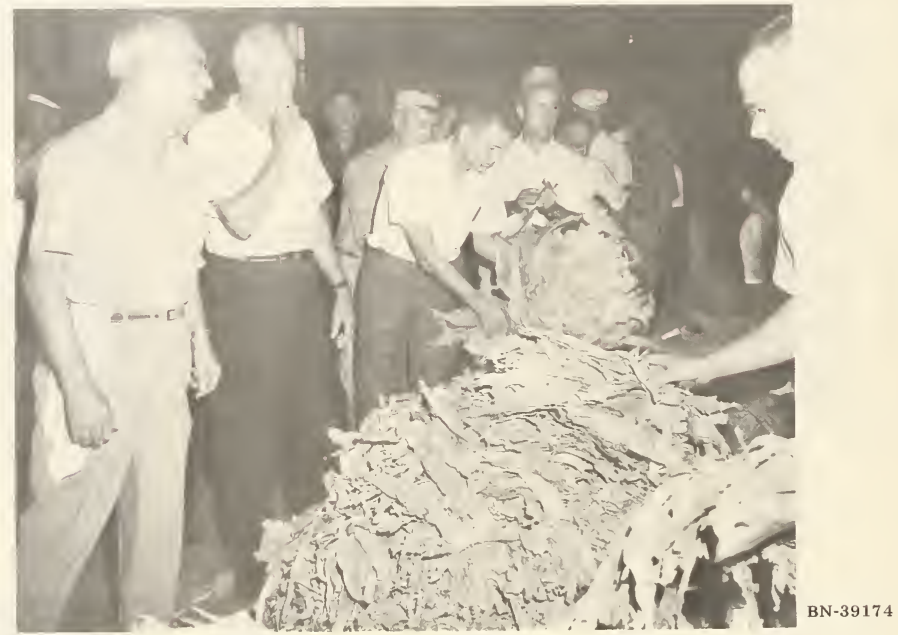

Figure 32.--Flue-cured tobacco auction sale in progress.

After the sale. As soon as the sale is underway, truckers begin moving the auctioned tobacco to side doors and loading it on trucks to be taken to the processing facilities of the various companies.

A farmer has the right to reject the bid price offered for any basket of his tobacco. He does this by "turning" the ticket, that is, by folding it with a crease, tearing off a portion, or otherwise mutilating it. Such lots are usually "dressed up" and put back in line for later sale on the same warehouse floor. It is assumed that, at the second sale, it will be bid in at a higher price. However, the grower may take the tobacco to another warehouseor market. 
The grower receives payment for his tobacco from the warehouseman on the same day it is sold. Clerks figure the amount due on each basket immediately after the sale. Selling charges are deducted and a check is issued the farmer against the warehouse account. Buyers usually settle with the warehouseman within a few days after the sale. Selling charges vary by types of tobacco, ranging from 3 to 6 percent of the value.

Loan program on auction markets. Government price support is offered for all types of tobacco sold at auction where growers have approved marketing quotas. Under the program a price support level is established for each grade of tobacco. If the buyer's bid price on any basket of tobacco is not more than the Government loan rate for the grade, the grower may accept the loan rate. In this case he is paid in the usual way by the warehouseman, who is in turn reimbursed by the applicable cooperative association receiving the tobacco under loan. The cooperatives operate with funds borrowed from the Commodity Credit Corporation. Tobacco which cooperative associations receive from farmers under the loan program is sold through regular trade channels. If any net profits are realized, they go to the growers, but any losses are assumed by the Commodity Credit Corporation.

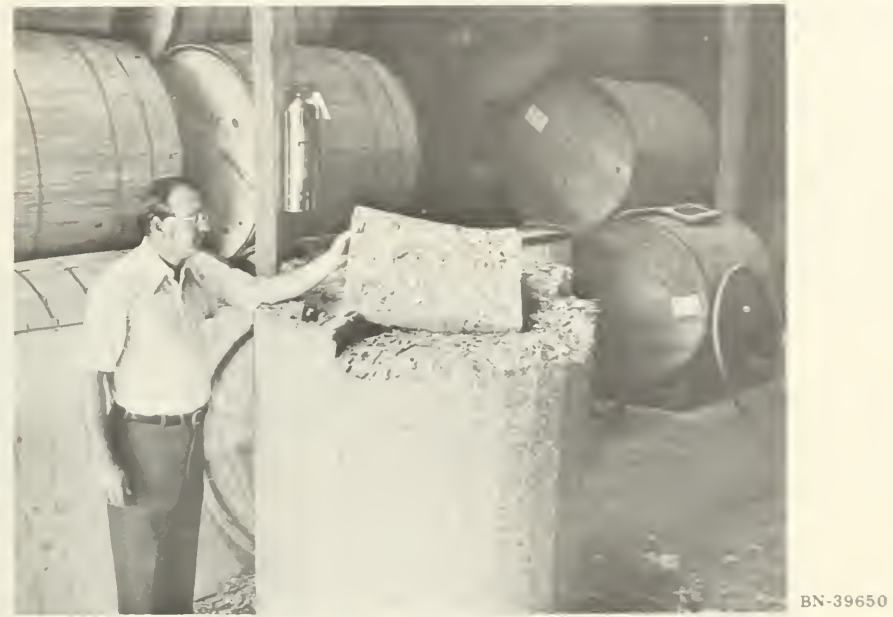

Figure 33.--A sample of "strips" beld by the Flue-cured Growers" Cooperative ready for inspection by buyers.

Country Sales - Fire-cured

In addition to sales of fire-cured at auction, a large quantity of this tobacco in the Kentucky and Tennessee area (averaging over 20 percent of the crop in the last two years) is sold directly at the farms. In earlier years, this farm or "barn-door" buying of the leaf was practiced to an even greater extent than it is today. Buying is done by large concerns looking for choice crops at advantageous prices. 
Prior to the development of the "loose-leaf" auction system of sales, growers packed their tobacco in hogsheads for delivery to commission agents. This was much the same procedure as was followed in the very early days of the country. Originally, the grower received a negotiable receipt for each hogshead delivered, before inspection and final sale. In the early 1800's, the practice of sampling the hogsheads and selling by auction established the first form of sale by the auction system.

Today, the only such hogshead market in operation is the "closed-bid" auction at Cheltenham, Md., which sells a small quantity of the Maryland tobacco. The tobacco is delivered to the marketing association which operates as the commission agent. After the State inspectors take samples from the hogsheads and affix the State seal, the samples are made available for examination by prospective buyers. The buyers submit "closed" or sealed bids on individual hogsheads; these bids are opened at a specified time and the highest bid is accepted subject to grower approval.

Since the establishment of the loose-leaf markets in Maryland in 1939, almost all the tobacco grown in that State has been sold on the auction floors.

Cigar-leaf Marketing (Country Sales)

In most of the cigar-leaf tobacco districts, farmers contract for the sale of their tobacco at the farm, a system known as "barn-door" marketing. This may be done during the growing or curing season, or after it has been cured, stripped, and baled. Buyers may be cigar or chewing tobacco manufacturers, independent packers, or their representatives. Although competitive bidding exixts in the sence that various buyers inspect the tobacco and make offers, competition is not as apparent as in the auction method of sales.

The buyers travel through the producing districts during the growing season, and note the progress of individual crops, as well as the changes in the acreages and crop prospects, as compared with other years. In this way they keep themselves informed on the location of desirable crops.

Sales may be at a flat price per pound for the entire crop; or, as is more common, at separate rates per pound for the two main groups made at stripping: (1) those suitable for cigar-manufacturing purpose, and (2) those known as stemming grades suitable primarily for the manufacture of chewing tobacco.

Cigar wrapper is grown under almost every kind of arrangement imaginable. Sometimes the buyer rents the land, hires the owner as foreman, and has him grow the tobacco for his (the buyer's) account; and in some cases the buyer and farmer each contributes certain specified items of cost and each shares in the proceeds in relation to this contribution. A common practice is the growing of the tobacco by the manufacturer himself on his own land. Sometimes a farmer, who thinks he has an unusually fine crop and believes the prevailing market will improve, has his tobacco sorted, sweated, packed, and stored for sale at a future time. 
Loan program in the cigar-leaf areas. Price sunnort loans are alsn available in the cigar leaf areas (except shade-grown) where marketing quotas have been approved. The cooperative associations, operating under contract with the Commodity Credit Corporation, arrange for receiving, grading, packing, and sorting the tobacco. Any eligible grower may deliver his tobacco to the receiving point, where a Federal inspector places a grade on it. If he accepts the loan rate for the grade, he receives the proceeds of the loan from the association, payment being made with funds borrowed from the Commodity Credit Corporation. In case he decides not to accept the loan, he may withdraw his tobacco. As explained under the auction system above, tobacco which cooperative associations receive under the loan program is sold through regular channels. Any net profits realized go to the growers, but losses are assumed by the Commodity Credit Corporation.

Figure 34.--Farm bales of Connecticut binder being delivered to the Conn-Mass Cooperative.

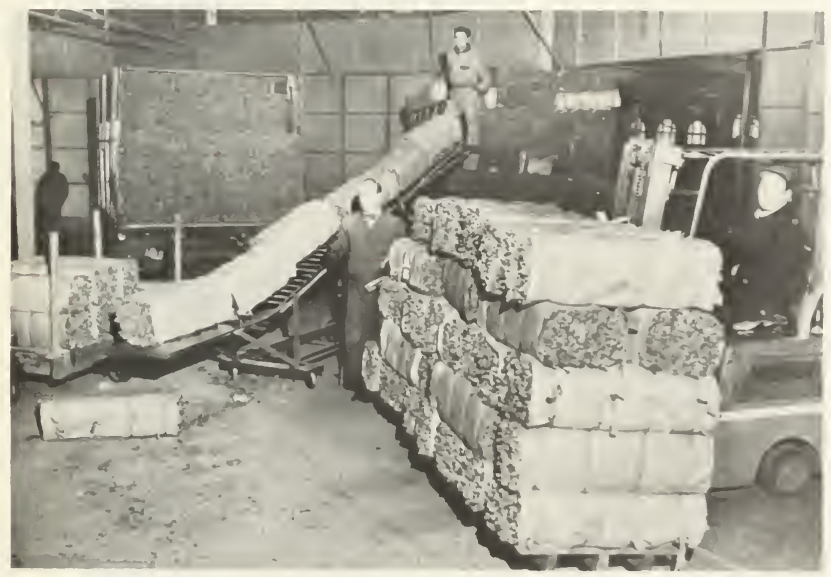

$\mathrm{BN}-39173$ 
Tobacco in its freshly-cured state as marketed by growers is not suitable for manufacturing purposes. Aging is required to complete its development. This involves chemical change, and in many respects may be regarded as an extension of the curing process. The taste of freshly-cured leaf is unpalatable and the aroma is biting and pungent. Aging improves the aroma and tends to eliminate rawness, harshness, and, in part, the bitter tasto which characterizes the leaf when it is first cured.

Tobacco is normally marketed in "higher order" (containing more moisture than is desirable for storage) and the moisture level must be reduced or the leaf will decay or deteriorate in storage. As soon as it goes into the hands of the dealer or manufacturer, tobacco is rapidly prepared for storage.

From the standpoint of handling and preparation for storage, U.S. tobacco falls into two groupings; auction areas (types 11-37) and cigar leaf areas (types 41-62).

Auction Market Areas

The tobacco sold in the auction market is packed in hogsheads or cases for storage and aging. Hogsheads are round barrel-type containers usually about 4 feet in diameter and 4 to 5 feet in height. The use of hogsheads dates back to early colonial days when the grower packed his own tobacco and had to get it to a river port. These barrel-like containers could be rolled along the roadways leading to the ports. Some tobacco that is to be exported is packed in boxes or cases. A hogshead of dry tobacco will weigh 950 to 1,200 pounds depending on the type and method of packing. A case weighs about 450 pounds.

The process of preparing tobacco for storage in hogsheads is known as redrying and all tobacco sold at auction, with two notable exceptions, is handled in this manner. The two exceptions are Kentucky-Tennessee fire-cured tobacco which can tolerate a higher moisture content and is often packed with no redrying at all, and Maryland tobacco which is normally sold in a very dry condition not requiring any redrying.

The redrying process involves (1) the almost complete removal of moisture from the tobacco and (2) the application of a uniform moisture content throughout all the leaf. Redrying is the most expeditious method of getting the tobacco into the proper order (condition with respect to its moisture content) for storage. Uniform moisture content helps to reduce breakage in packing, and aids in the "aging and fermentation" of the leaf. Most of the redrying facilities are concentrated in towns where the larger auction markets are located. Modern redrying plants are high buildings containing highly sophisticated and expensive equipment. During the height of the buying season many plants will operate 24 hours a day. 

The tobacco is moved from the auction floor to the "receiving room" of the redrying plants where the individual sheets or baskets are arranged according to grades or blends of grades.

In the flue-cured area, where all tobacco is sold in loose-leaf form, the usual procedure is to empty the contents of each sheet onto a moving conveyor belt which passes a row of workers who physically inspect the tobacco and remove damaged or out-of-grade leaves, and foreign matter. After passing this "picking" line the tobacco is either fed directly into the redryer or routed through thresher separators that separate the leaf tissue from the midrib or stem of the leaf before entering the redryer. Most flue-cured tobacco is stemmed prior to redrying.

In the stemming operation the leaf is fed onto a rotating toothed cylinder which passes through stationary combs thus stripping or shredding the leaf tissue from the stem. Separation is accomplished by air currents which allow the heavier stems to fall to the bottom. The stemmed leaf is referred to as "strips." Another variation is played on this basic theme. Some manufacturers, and most dealers, will "tip" the leaves before threshing. The tangled leaves are oriented on the belt, insofar as possible, with the tips against an adjustable tipping board so that rotary knives can cut off the upper one-third or tip portion of the leaf. These tips bypass the thresher and rejoin the stemmed lower portion at the entrance to the redryer. More labor is needed for this operation but thresher capacity is greatly increased and the overall yield is greater than whole leaf threshing.

The strips and tips enter the redrying machine on a conveyor belt. There are three separate compartments within the redryer: (1) In the first compartment all moisture is removed by heated air; (2) the second compartment is a cooling chamber to prenare the tobacco to receive moisture; (3) a controlled and uniform amount of moisture is added to the leaf in the third compartment. The entire passage can take from 30 to 45 minutes with temperatures reaching $160^{\circ} \mathrm{F}$ and final moisture contents varying less than 1 percent. Upon leaving the redrver the tobacco is immediately placed in hogsheads and packed under pressure.

Burley tobacco is marketed in bundles or "hands" and the redrying procedure requires different techniques. As in flue-cured, most burley is now packed in strips. After leaving the receiving room the bundles are inspected and placed on a belt against the tipping board and the bundles are broken after tipping. Hands from several baskets are mixed to produce a more uniform blend. The rest of the process is identical to flue-cured.

If the tobacco is not being stemmed the bundles are left intact and the hands placed on metal rods along a "hanging-line" for blending and inspection. From here the filled rods are placed on a chain conveyor for the trip through the redryer. 
Methods of preparation for storage other than redrying are practiced in the Kentucky and Tennessee fire-cured district, and in Maryland. Kentucky and Tennessee fire-cured tobacco purchased by snuff companies is packed directly into the hogsheads as it comes from the warehouse floors, without any further drying. Although the trend is toward redrying by other Durchasers in this area, some is still handled by the old method of hanging and bulkine for a short neriod before packing in the hogsheads. In the Virginia fire-cured district, some tobacco is still hung in racks for natural air drying for a period of several months before packing into hogsheads. In Maryland, tobacco is marketed in a very dry state by the growers, and it will keep, when nacked in the hogsheads, without further drying. However, some companies do redry their purchases to insure the more uniform distribution of moisture that will result in better aging of the tobacco.

Storage. The packed hogsheads of tobacco are moved from the redrying and packing plants to the storage warehouses of the various companies. Most of these warehouses are one story high, with a steel or wood framework and metal siding and roofing. The sides are flared outward within 4 or 5 feet of the ground, and in the offset thus formed, heavy screen wire is placed for ventilation. The warehouse usually has a concrete driveway running lengthwise through the center for convenience in moving the hogsheads into place. They may be stacked in tiers three or four high on their sides or placed on end five or six high. The latter is becoming more popular since clamplift trucks can handle the heavy work and warehouse space is better utilized.

Within the storage warehouse, during the fermentation process, tobacco passes through a series of "sweats," and undergoes chemical changes similar to those that take place in any closely packed, moist vegetable matter. "Siveat" is a trade term used for the natural fermentation process of tobacco, during which chemical changes that take place give it a sweeter, mellower flavor. The termperature rises in the closely packed, moist tobacco, and certain volatile products are thrown off. The reduction of nicotine in fermentation has an important relationship to the smoking quality of the tobacco; that is, its freedom from pungent, biting, unnleasant taste and aroma. The tobacco annears to take on additional moisture, but there is actually a loss of moisture when the sweating period is finished. Colors tend to darken and become more uniform. As a rule, around two or three years of storage are required for the necessary aging by natural fermentation. Tobacco that is to be exported is not usually held in storage in this country unless the customer desires the aging, to be done here.

\section{CIGAR-LEAF AREAS}

In handling cigar leaf, some is placed in bulks and fermented before nacking for storage, and in some, fermentation occurs during storage.

The cigar-wrapper types are fermented by the process of bulk-sweatins. The tobacco is taken directlv from the curing barns to the packing houses, where it is bullt into bulks of varying shapes and sizes, according to local custom. The bulks of shade tobacco are usually 5 or 6 feet wide, 12 to 16 feet long, and 8 feet high, and contain 4 to 6 thousand pounds of tobacco. 


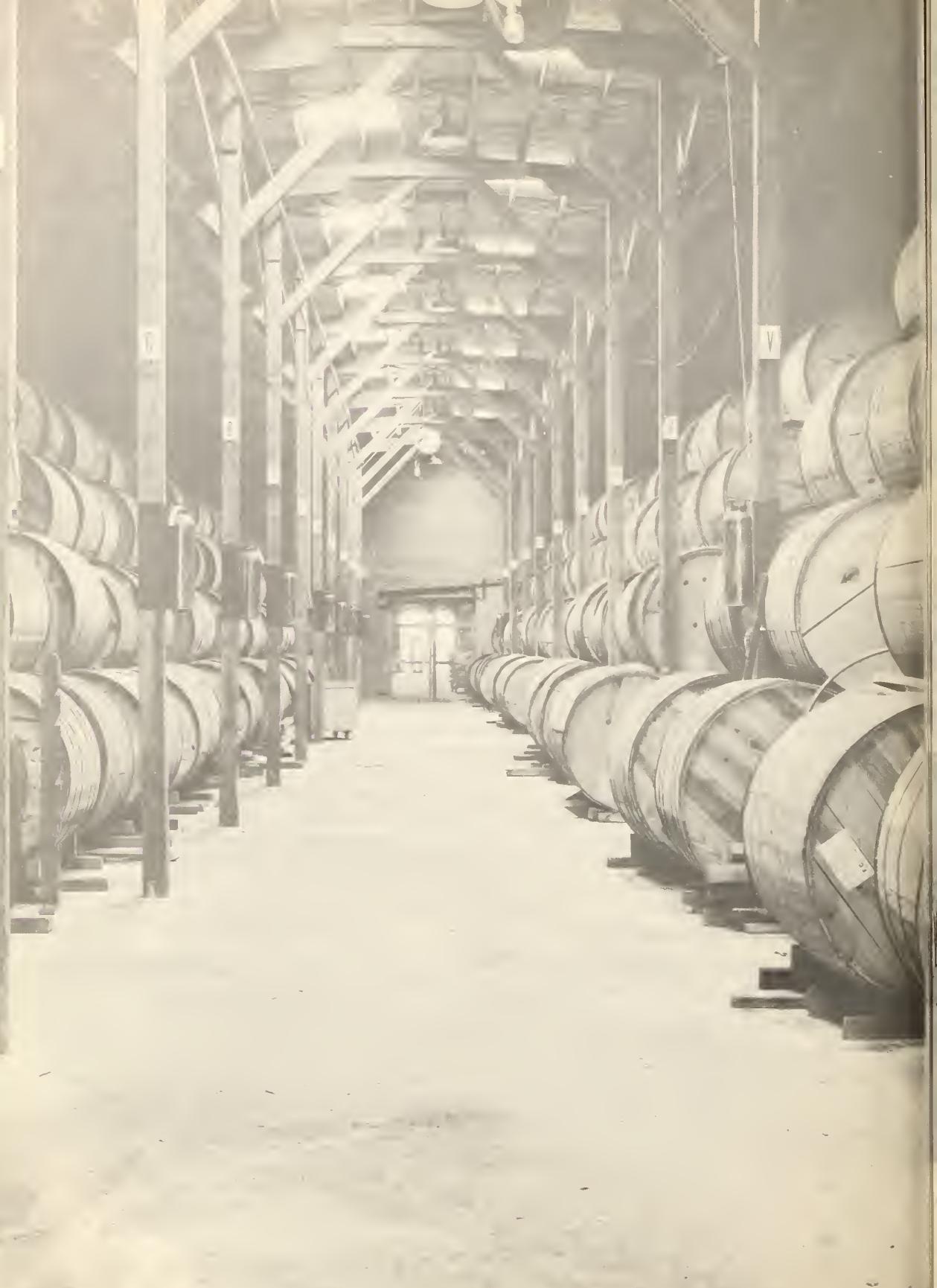


Tobacco bulks are built with great care and kept under close watch. Recordings are made of the temperature in the center, and the bulks are "turned" or rebuilt every few days until fermentation has been completed. The tobacco is further sorted - leaf by leaf - sized, retied, packed into bales, and stored in a cool place.

The cigar filler and binder types (except Puerto Rican) normally receive only a limited amount of handling prior to storage for aging. Most of the tobacco is stored in farm bales as delivered by growers. These bales are rectangular-shaped packages containing 40 to 50 pounds of tobacco wrapped in brown paper with open ends. The tobacco is arranged with the butts to the outside and the tips overlapping in the middle. The bales are often placed in a heated sweat room several weeks before going into permanent storage.

The use of reconstituted tobacco sheet for the inner binder of cigars makes careful sorting of the leaf unnecessary. Only a tiny portion of binder tobacco is now purchased for use as natural binder in premium cigars.

In the case of the filler types, the trend is toward short filler, and it is also unnecessary for these types to be carefully sized or sorted. Most tobacco used as short filler is bulk-sweated.

- Figure 37.--Interior of a tobacco storage warebouse.

N-29180

Figure 38.--Redried tobacco en route to storage warebouses.

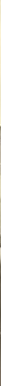




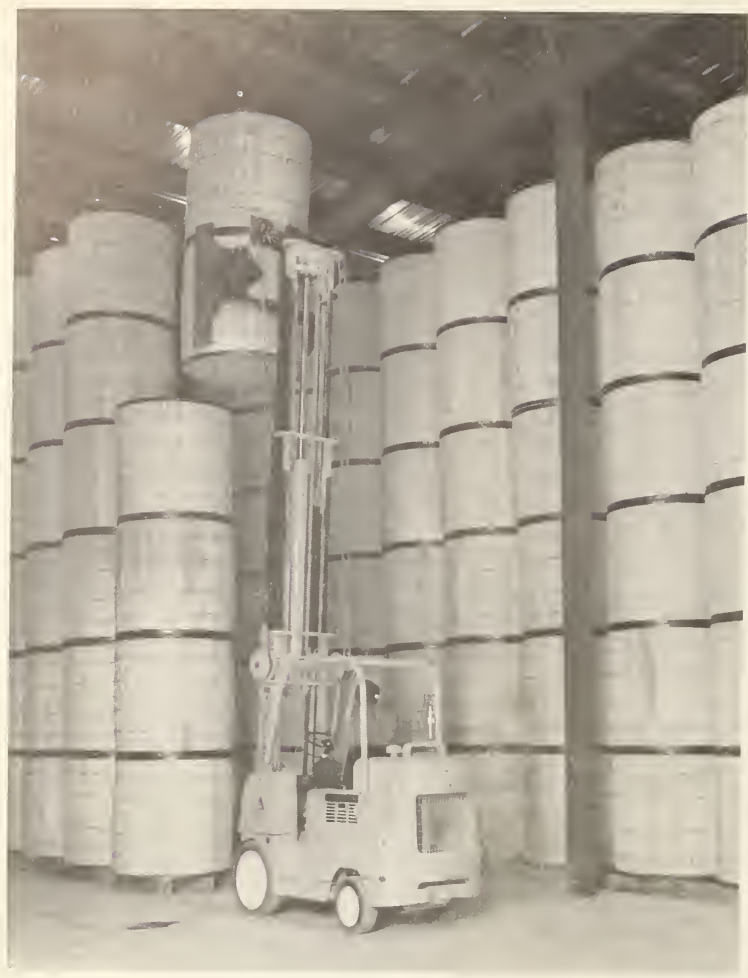

$\mathrm{BN}-39167$

Figure 39.--This new method of storing hogsheads saves labor and increases warebouse capacity.

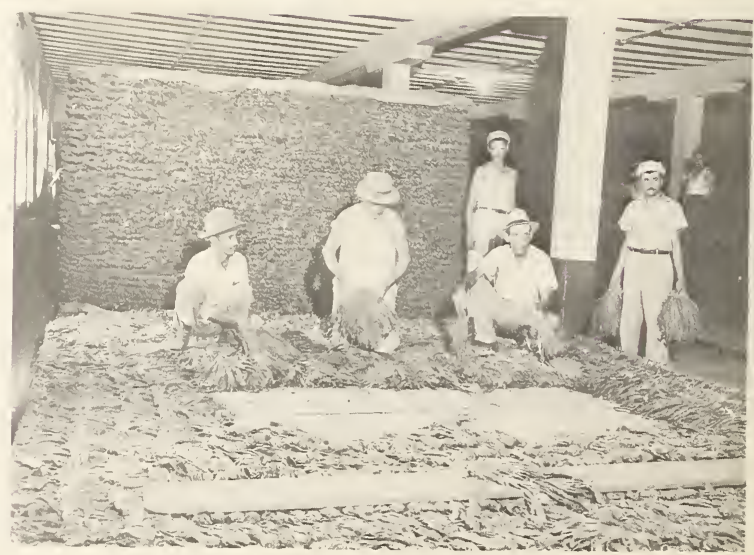

Figure 40.--Puerto Rican tobacco being bulked. BN-39168 


\section{MANUFACTURING INDUSTRY}

Cigarettes currently account for about 80 percent of the tobacco consumed in the United States. The remainder is about equally divided between cigars and manufactured tobacco (smoking, chewing, and snuff). The trend towards cigarettes developed rapidly. In the early 1920's, cigarettes accounted for only one-fourth of U.S. tobacco consumption, while manufactured tobacco made up 50 percent of the total. Manufactured tobacco has now declined to less than 10 percent of total consumption as consumers have turned to lighter, milder forms of tobacco.

In the colonial period the export trade was the only commercial outlet for tobacco leaf. After the Revolutionary War, small manufacturing plants began to appear, and in 1790,29 million pounds were used in manufacture. The product was a roll or twist form, from which portions were cut for chewing or smoking, or grated for snuff. Early in the $1800^{\prime} \mathrm{s}$, the manufacture of cigars began to assume importance. Imported Cuban leaf was principally used in their production. However, as the domestic cigar leaf types were developed, first in Connecticut and Massachusetts, and later in the Wisconsin and Pennsylvania area, these were combined with the Cuban imports in cigar manufacture. By 1860,45 cigar factories were in operation.

At the outbreak of the Civil War, the manufacture of chewing tobacco had reached its peak. The leaf used in this product was a new type being grown in Virginia and North Carolina, and was the forerunner of modern flue-cured types. During the last quarter of the century, the manufacture of fine-cut chewing and smoking (mostly granulated) came into prominence in which leaf of another new type, White Burley, was used.

An outstanding feature in tobacco manufacture in the last quarter of the 19 th century was the development of the cigarette-making machine, which first came into use in the early $1870^{\prime} \mathrm{s}$. Flue-cured was the principal leaf used at first and toward the end of the century, imported Turkish assumed importance in the development of the blended cigarette. Fifteen years after cigarettes were first made by machines, annual production passed the billion mark and by 1895, 4 billion were manufactured. Current production is around 600 billion.

Today, about 1.3 billion pounds of domestic and $275 \mathrm{million}$ pounds of imported leaf are used in the manufacture of tobacco products in this country.

Taxes. In almost every country in the world tobacco has been a popular item for taxation. In the United States a Federal tax on manufactured tobacco products was established in 1862, but the tax on manufactured tobacco (smoking, chewing, and snuff) was repealed effective January 1, 1966. The revenue derived from cigars and cigarettes now amounts to over 2.1 billion dollars annually.

In addition to the Federal tax, all 50 States and the District of Columbia impose taxes on one or more tobacco products, and revenue from such taxes now totals nearly three billion dollars yearly. Further taxes are levied on tobacco products by some city and county governments. 
History records that tobacco was used by the American Indians in each of the three ways in which it is used today, and changes in usage through the years relate to the comparative popularity of these three forms. While consumer habits are not subject to sudden change, in the long-time sense there have been marked shifts in forms of use. The general direction has been from "strong" tobacco to "mild," from cigars to cigarettes, from chewing to pipe smoking, and from dark heavy-bodied types to lighter types. Changes in patterns of consumption usually entail shifts in the types of tobacco used in manufacture, and consequently shifts in the production of those types.

\section{The Cigarette Industry}

The cigarette industry is by far the most important part of tobacco manufacturing, both in use of the leaf and in volume of sales. Its extraordinary development during the present century presents one of the most phenomenal aspects of tobacco history. This has been due to two principal factors--the perfection of the modern highly efficient cigarette making machine and the development of the blended type of cigarette. The manufacturing of cigarettes is so highly automated that the cost of producing a pack of cigarettes (excluding tobacco material) is estimated at about 2 to 3 cents per pack.

The industry has always been dominated by a few concerns. Today, 99 percent of the cigarettes manufactured in the United States are produced by six companies. The manufacture of cigarettes had its beginning in this country 1 ) in 1872, when the first cigarette machine was invented, and by 1890 annual production had reached $2-1 / 2$ billion. In these earlier years, cigarettes were made almost entirely of one kind of tobacco--flue-cured, burley, or oriental, but in 1913 the blended cigarette of American and Oriental tobaccos appeared on the market, and became immediately popular with consumers. Flue-cured and burley are the principal tobaccos used in making cigarettes. Most of the Maryland tobacco consumed in this country goes into blends, along with imported "Turkish" or Oriental tobaccos.

The following figures show approximate percentages and amounts of these kinds of leaf used in American cigarettes, as a whole (fiscal year 1971-72):

\begin{tabular}{|c|c|c|}
\hline \multirow[b]{2}{*}{ Type } & contained in blends & Million pounds \\
\hline & Percent & Farm weight \\
\hline Flue-cured & 47.3 & 618 \\
\hline Burley & 34.8 & 455 \\
\hline Maryland & 1.5 & 20 \\
\hline Imported leaf & 16.4 & 215 \\
\hline & $\overline{100.0}$ & $\overline{1,308}$ \\
\hline
\end{tabular}

I/ Cigarettes in their first primitive form are said to have been introduced by the Turks around 1855; but at that time, although they were paper-wrapped, they were known as "cigars." 
Upon completion of the aging period, hogsheads of tobacco are removed from storage and placed through a conditioning process in the factory. The moisture level is raised to permit handling of the strips without unnecessary breakage or reduction of quality. Measured quantities of different grades of Flue-cured, Burley, and Maryland are blended along with proper proportions of oriental tobacco. Care is used in blending to keep the product consistent in smoking quality and taste. The blends of each manufacturer are carefully guarded secrets so that it is not known what proportions of each type of tobacco go into any particular brand of cigarette.

After the strips are blended, certain conditioning agents and humectants are applied in order to improve the handling and keeping characteristics of the tobacco. In further processing, special formulas of casing materials (sweeteners) are added to enhance the smoking quality of the products.

Cigarette manufacturers make extensive use of reconstituted tobacco to utilize the fine particles, scrap, and portions of the stems. These are combined in confidential processes to make a sheet which can be shredded with the natural strips of tobacco for cigarettes.

The blended tobacco is conveyed to the cutters where it is pressed into solid cakes called "cheese." The "cheese" is subjected to a slicing operation which cuts the tobacco into slender shreds of the right consistency and size for well-formed cigarettes.

Although tobacco used in the manufacture of cigarettes is fully flavored, additional substances are added to most blends to further enhance the full smoking flavor and aroma. These flavoring agents may be substances or extracts derived from honey, maple, rum, fruit juices, apple, fig, vanilla, tonka beans, grapes, berry wines, licorice, cocoa, and menthol.

Along with the addtiion of the enhancing agents, humectants are added to insure proper moisture content after the product has moved into trade channels and after the pack has been opened. Glycerine is a typical chemical used for this purpose by many manufacturers.

\section{Modern Cigarette-making Machines}

Present day cigarette-making machines employ modern engineering techniques which allow high production output with the assurance of uniform product quality.

Cigarette paper is supplied to the cigarette-making machine in large reels. As the reel of cigarette paper unwinds, the brand name is printed at uniform spaced intervals. Cigarette tobacco is fed to the cigarette-making machine via a pneumatic conveying, system and is metered in a uniform stream onto the cigarette paper to form a continuous rod. 


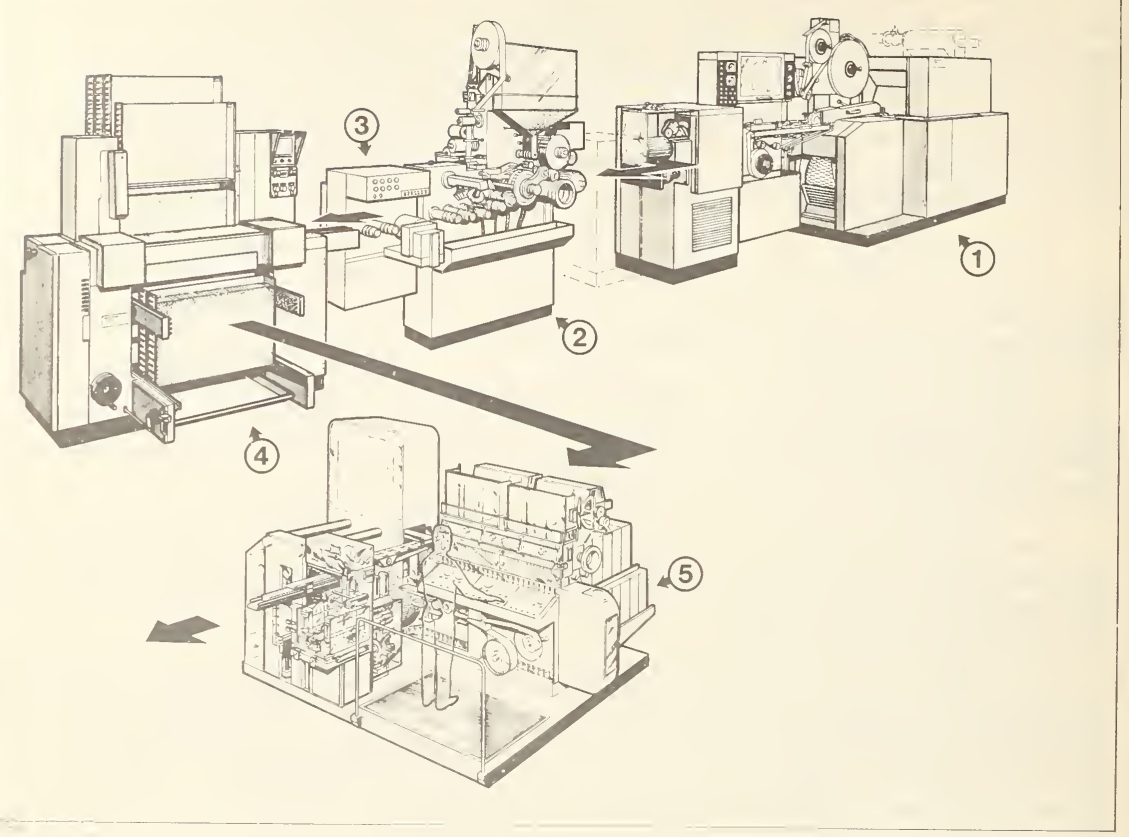

DN-3327

Fignre 41.--Typical arrangement of cigarette making and packing macbinery.

1. The making machine combines tobacco and paper into a continnous rod that is cut into individnal cigarettes.

2. The tipping machine receives the cigarettes and attaches the filter.

3. The inspection device monitors each cigarette and performs a series of tests such as density, weight, length, and circumference.

4. Finished cigarettes are collected in trays that are automatically fed to the packing machine.

5. The packing machine puts the correct number of cigarettes into eack pack and, after inspection, wraps them for delivery to other machines for packing into cartons and crates. 
This continuous rod is sealed and then cut into the required lengths for the particular brand being produced. In the case of nonfilter cigarettes, these cut cigarettes are placed by machine into suitable containers for delivery to a packaging system.

Popular cigarette lengths currently include regular, usually $70 \mathrm{~mm}$, $\mathrm{king}$ size, usually $85 \mathrm{~mm}$, and super king, usually $100 \mathrm{~mm}$. The average circumference of all cigarettes is $25 \mathrm{~mm}$, but this can vary slightly according to brand.

\section{Filter Cigarettes}

The majority of cigarettes produced in the U.S.A., presently, are "filter-tipned" (estimated at over $80 \%$ ). Cigarettes with filters are produced in exactly the same manner as nonfilter cigarettes up to the point of cutting the continuous rod into individual lengths. Generally speaking, the filter plug is about $20 \mathrm{~mm}$ for king-size cigarettes, and $25 \mathrm{~mm}$ for the super kings.

In order to produce filter-tipped cigarettes, additional machinery is linked directly to the cigarette-making machine to receive the cut lengths of tobacco rod. A measured length of filter material (usually cellulose acetate) is placed between two sections of finished cigarettes. A "tipping" paper material, usually either of cork or opaque white appearance, is wrapped around the filter, sealing it to the ends of the two cigarettes. This double cigarette with the filter in the center is then cut exactly through its middle to form individual filter-tipped cigarettes, which are automatically placed into suitable transfer containers for delivery to a packaging system.

Modern cigarette-making machines are fitted with control units which monitor and automatically correct the weight of the tobacco used in the cigarettes produced and also inspect each cigarette for quality defects. Cigarettes which do not meet rigid quality standards are automatically rejected.

\section{Packaging Systems}

Modern cigarette factories now use packing machines, machines for transparent overwrap, and cartoning machines in an "in line" operation rather than as separate units. This improves product flow and avoids unnecessary handling.

Filled containers of cigarettes are fed by machine into the hooper of a packing machine. These cigarettes are then arranged into groups of twenty cigarettes and inspected by an electromechanical device. Each group of twenty cigarettes is wrapped in aluminum foil, and a paper label bearina brand markings is wrapped around the aluminum foil, leaving one end exposed. A small sticker or closure is fixed to the paper label to close it over the exposed aluminum foil.

The comnleted packs are fed direct into another machine where they are overwrapped with cellophane or similar film to preserve freshness. A strip of tear tape material is fixed to the overwrapping film in order to provide 
easy access to the packaged cigarettes. The overwrapped packs pass directly into a cartoning machine where ten packs each are placed into a cardboard carton. The completed cartons, sealed on all four sides, then travel via a conveyor belt to another machine which places them into suitable shipping containers for domestic distribution or for export.

Cigarette paper used in manufacturing cigarettes was, prior to 1940, almost entirely imported. At the present time, however, most of the paper is manufactured in this country from domestically grown flax straw. The flax straw fiber is repeatedly bleached and refined during the manufacturing process. The paper must be very thin, and at the same time durable enough to prevent tearing or breaking on high speed machinery; it must burn slowly and evenly at the same rate as the tobacco; it must contain tiny air passages, or pores, to control the amount of dilution of the smoke by air (and consequent flavor and nicotine content per puff); and it must be completely tasteless. The paper is first rolled in wide sheets on large bobbins, and later it is slit into widths proper for the circumference of the cigarettes.

The cigarette industry currently employs about 33.0 thousand production workers. Additional thousands are employed in management, accounting, sales, etc. Around 576 billion cigarettes were manufactured in 1971, mostly for domestic consumption. However, about 32 billion were exported to over 100 foreign countries throughout the world and another 17.5 billion went to the Armed Forces overseas, to ship stores, as shipments to Puerto Rico, etc. Consumers spent about 11.5 billion dollars for the 555 billion cigarettes consumed in the United States in 1971. Per capita consumption (18 years and over) is about 200 packs annually. The Federal Government receives over 2.1 billion dollars annually from the eight-cents-per-pack excise tax rate, and nearly 3 billion dollars is collected yearly among the 50 states, the District of Columbia, and local governments. The State tax rates range from 2 cents to 21 cents per pack (as of April 1, 1972).

\section{The Cigar Industry}

The cigar industry in this country began in homes on tobacco-growing farms. 29 Shops employing skilled cigarmakers began to appear after 1800 , and larger factories gradually evolved from these. The making of cigars on farms eventually disappeared, but the practice of making them by hand in the small shops persisted as an important phase of the industry throughout most of the 19th century.

With the perfection of cigar-making machinery during this century, the industry rapidly evolved into fewer and larger establishments. In the last 25 years alone, the number of factories producing cigars has dwindled from 1,800 to about 300, and production has increased from 5 to over 8 billion. A11 cigars, except the most expensive, are now made by machines.

2/ The first cigars known here were imported from the Spanish West Indies and were called "segars." 
There are three components of the cigar--filler, binder, and wrapper. For the manufacture of some cigars, imported leaf is used for part or all of the cigar. Presently, less than one-half of the cigar leaf used in the industry is domestically grown.

Reconstituted tobacco sheet. "Reconstituted sheet" is now used as a substitute for natural cigar binders on most cigars, and an increasing percentage also have reconsituted wrappers. Those with reconstituted wrappers often do not have the inner binder.

In manufacturing this material, tobacco is ground into a fine powder, mixed with a cohesive agent, and rolled into a flat sheet of uniform thickness and quality. The moisture is controlled throughout all the various stages of the production, and the material is so made that not only have the taste and aroma of the natural leaf been preserved, but the burning quality has been improved.

The use of reconstituted sheet results in substantial savings both in leaf and labor costs. Natural leaf binders have to be nearly perfect, and are therefore costly. When these are used, they are first stemmed, and the stems discarded. Generally each half of a stemmed leaf will yield two to three binder nieces and the trimmings go largely into the manufacture of loose-leaf chewing, a lower value outlet. In tobacco sheet, the entire binder leaves are used, even though they may be broken or damaged. There is no waste or trimmings in cutting the binder, as it is cut to a parallelogram shape, which uses all the sheet.

The savings in labor cost, as well as in leaf cost, is also an important factor in the develonment of this processed sheet for cigar-binder purposes. Natural binders must be hand-fed into the cigar-making machine but the sheet is fed automatically from a spool, thus reducing the workers required from 2 to 1 on most machines (fig. 42).

The use of sheet as wrappers is not as widespread as binders, but the potential saving in this area is also considerable, both in leaf and labor costs.

The filler tobacco is first fed into a hopper of the producing machine to make the core or center part of the cigar. This filler may be made of long fragments of leaves, the length of the cigar, or of short-shredded nieces bunched together. Yost cigars are made with short filler. The filler nortion is blended and shaped, and the binder, either natural or sheet, cut and wranped around it. Next, the wranper is cut and applied and the end sealea. Machines can turn out standard size cigars at the rate of 800 to 900 per hour. Yore recently new high-speed machines have been develoned which, usting reconstituted binder and wrapper, are capable of producing 700 or more cigarillo-size cigars per minute. 
Figure 42.--A modern cigar making macbine using shori filler to bacco
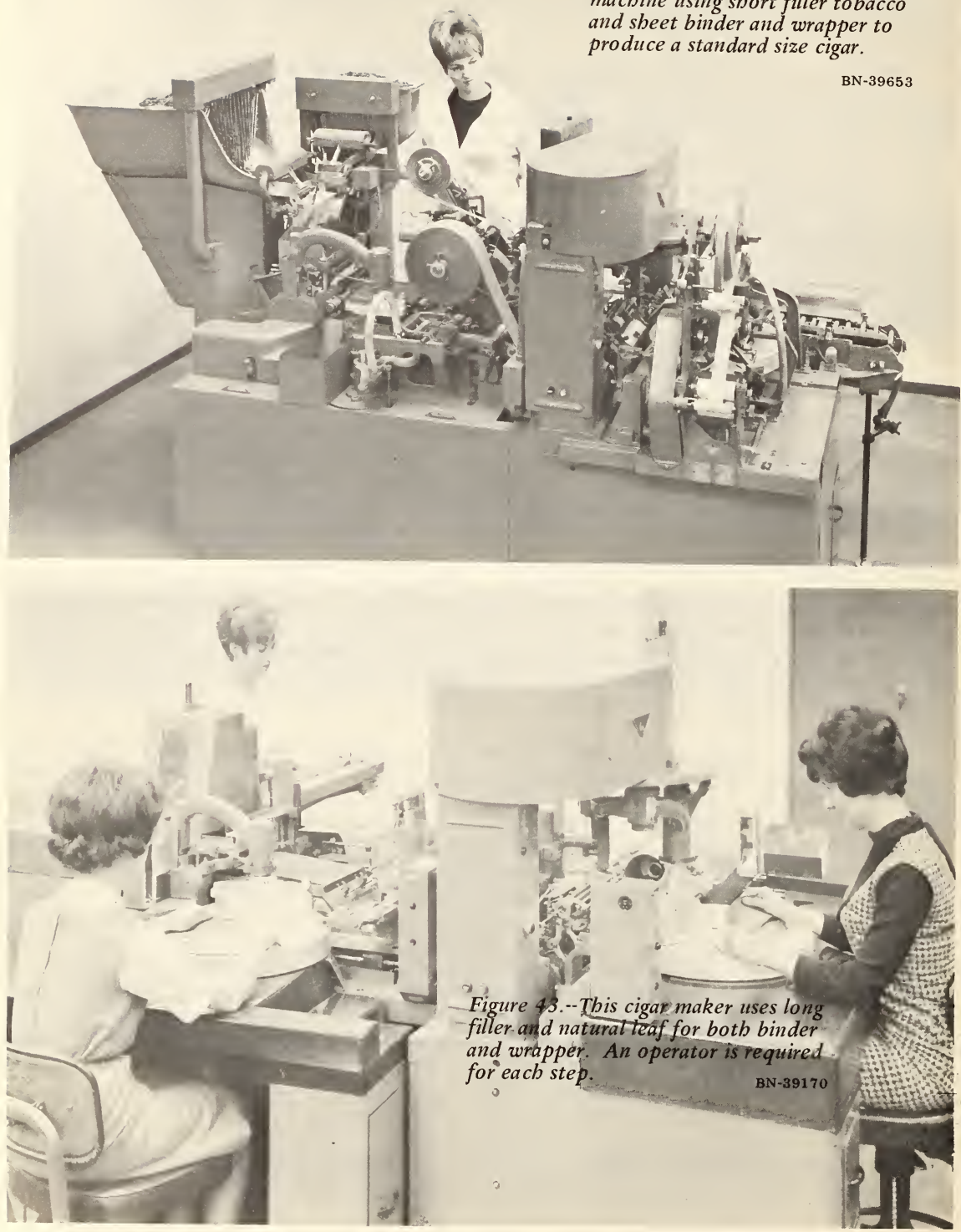
A few of the higher-nriced cioars are still handmade. The filler Dart is blended and shaned, and wranned with binder leaves. Then it is nlaced into the lower half of a mold block containing usually 2 n individual molds the shane and size of the finished cigar. The unner half is placed over the mold block and held in nosition under nressure for several hours. The molded bunches are taken out one at a time, and the wrander rolled on. Wranners nust be the finest of the tobaccos used in cigars. of good color, and without imnerfections. Fach wranner leaf, wich has first been cut to the right size is rranned snirally around the cisar, beginning at the base, and tanered off to form the head. The end of the wranner is fastened with a gum naste, or similar material.

Tn makin? the very finest handmade cigars, no form or mold is used. These cigars are entirelv shaned, sized, and rolled by hand, on a sneciallv made board or block fitted with a knife for clinning the head and the end. A high degree of skill and dexteritv is refuired in making, uniformlv high grade handmade cigars.

Cigars are normally wranned individually in cellophane. A larce nrodortion are now nackaged in "five-nack" cellonhane-vrapned containers for handy merchandising by sunermarkets, etc. However, manv are still packed in boxes of $25^{\prime} \mathrm{s}$ and $5 n^{\prime} \mathrm{s}$. Formerly the boxes were made exclusively of Spanish cedar but nors most are of fiberboard. The cigars are carefully nacked according to color shade, so that each hox will be uniform in color.

About 15,500 nersons currently are emnloved in cigar factories. Current$1 \mathrm{y}$ over 8 billion cigars are nroduced annually in the Untied States and Puerto Rico. (Imnorts of cisars amount to about 50 million.) Anproximately 36 million nounds (farm-sales weight) of domestic leaf are used annually and another 86 million pounds are imported. Prior to the embargo in February 1962, Cuba was the most imnortant sunnlier. The Philinnines rank first now.

\section{THE MANUFACTURED TOBACCO INDUSTRY}

(Chewing, tobacco, smokins tobacco, and snuff)

At the nresent time, around $10 n$ factories manufacture chewing and smoking tobacco and snuff. Since 1918, when over 1.800 factories were onerating, this branch of the industrv has steadily declined, as consumer tastes turned to cigarettes. The neak snuff nroduction was 41.1 million pounds in 1929 , and has declined to about 26.5 million pounds at nresent.

Chewing Tobacco

The manufacture of cheving tobacco was at a high level un to 1918. Since that vear, which marked the befinning of the most ranid exnansinn of the cigarette industry, this form of manufacture has sharply declined. Currently four tvnes of cheving, tobacco nroducts are recognized: nlus, twist, fine-cut. and loose-leaf. 
Nearly all types of tobacco are used in the manufacture of chewing, even those that are primarily cigar and cigarette types. Although both flue-cured and burley are considered cigarette types, both owe their early use to the chewing tobacco industry, and continue to furnish some leaf for the manufacture of these products. The dark air-cured and, to some extent, fire-cured types go into various chewing forms; and cigar leaf is the principal kind of tobacco going into the loose leaf chewing product.

Plug is made of leaf tobacco pressed into flat cakes after the stems have been removed. The plug consists of two parts, filler and wrapper. Fillers consist mainly of the heavier grades of flue-cured, burley, dark air-cured, and some fire-cured tobacco. The wrappers are leaves carefully selected for fine quality and appearance but some brands use reconstituted tobacco as wrappers. Various saucing compounds are added to the tobacco, such as licorice, maple sugar, honey, etc. Two distinct kinds of plug are made--one flat or thin and moderately sweetened, and the other thick and heavily sweetened.

Twist tobacco probably originated on the farm where the grower found it convenient to make his leaf tobacco up into twists for future use. Twist is similar to that product known as roll tobacco, which was the very earliest form of tobacco manufacture. In making commercial twist, the leaf is stemmed and twisted into small rolls and folded. Most twist is treated with the same kind of saucing preparations used for making plug, but some is left plain. One-sucker, burley, and fire-cured are the types of leaf used in the manufacture of twist. Hand labor is used to a large extent in the small twist factories located in producing areas, but machine methods are used by larger firms.

Fine-cut tobacco, as indicated by the name, is made of finely shredded leaf, cut much the same as for the manufacture of cigarettes. However, some forms may be so finely cut as to appear coarsely ground, and closely resemble moist snuff. Some of it is heavily coated with saucing, like the thick plug. Burley and Green River are the principal leaf types used.

Loose-leaf chewing, unlike most other chewing and pipe-smoking products, is made almost entirely of cigar-leaf tobacco. Cigar leaf used consists of "stemming" grades, or those not suitable for cigar manufacture. Practically all the stems and some of the coarser fibers are removed before processing. Loose leaf chewing is also an outlet for broken leaves and "cuttings" from cigar manufacture. The product consists of irregular fragments or flakes of tobacco leaf, about $1 / 4$ to 1 inch in diameter, and put up in small packages. It is classified in the trade as sweet (heavily cased with flavoring materials) and plain.

Smoking Tobacco

The term "smoking tobacco" commonly refers to pipe tobacco, although considerable quantities of tobacco so classified are used in hand-rolled cigarettes. Smoking tobacco is manufactured in many forms, such as granulated, plug cut, long cut, cube cut, and others. Various types of leaf are used in the manufacture, but the most widely-used single type is burley. 
Most smoking tobacco is treated by the addition of heavy saucing materials, which contribute to the mildness and aroma of the smoke and prevent rapid drying out of the tobacco. However, some brands are only mildly flavored. A number of materials are used for flavoring such as tonka beans, the seeds of a tropical South American tree; and deer's tongue, the powdered leaves of the wild vanilla plant, a perennial herb that grows in pine barrens from North Carolina to Florida.

Granulated is one of the oldest and simplest forms of smoking tobacco. It is made mostly of burley and flue-cured types of leaf, but various blends are also used. The product consists of stemmed leaf broken into small flakes with added flavoring. Some rolled, flattened, and cut stems may also be added. Granulated smoking tobacco is popular for hand-rolled cigarettes. This form of tobacco is usually packaged in small cotton bags.

Long cut is cut coarser than fine-cut chewing tobacco. Long cut is usually used in mixtures of roll-your-own smoking tobacco.

Plug cut, (or cut plug), is made in much the same way as plug chewing tobacco, and then sliced to desired shapes. Its use today in the United States is very small.

Smoking tobacco (except granulated) is usually packaged in tins or molsture-proof pouches that can fit in coat pockets.

Snuff

Snuff was made and used in America before the landing of Columbus. A century or more ago its use was considered one of the distinguishing marks of the gentleman. Snuff-taking enjoyed a degree of elegance for abcut 200 years, but in more recent times its forms of use and the classes of users have changed. Contrary to popular belief, very little snuff today is sniffed or used through the nose. Most of it is "dipped," a term commonly meaning that it is used in the mouth (tucked between the lower lip and the gum) as a variation of chewing tobacco. Its use is probably centered in the South, and Northwest. Use of snuff is often heavy in some industrial plants where smoking cannot be permitted.

Production of snuff in the United States has never been large, but even today about 26 million pounds are still produced annually. Snuff is made principally from fire-cured; a small quantity of dark air-cured also goes into its manufacture. Some of the leaf is stemmed, but for the most part, the entire leaf is used and often additional stems are added.

After the leaf is aged, it is removed from the hogshead, cut into 1 to 2-inch pieces, and repacked for the "sweating" or fermentation process. After this period, it is dried, coarsely ground, and fed into revolving steel drums where rotarv rollers reduce it to a fine powder. This product is then strained through cloth, flavored, and finally packaged, usually in small tin boxes. 
Snuff is manufactured in many forms. Some of the principal forms are fine and course, dry and moist, plain and toasted, and salted, sweetened, flavored and scented. The different kinds are known by such names as Scotch or dry (strong or sweet) and moist (coarser than dry snuff and closely resembling fine-cut chewing). Some of the essential oils and spices used for seasoning are cinnamon, cassia, attar or roses, wintergreen, mint, etc.

The chewing, smoking and snuff industry currently employs less than 5,000 production workers. In 1971, the following amounts of the different products were manufactured: chewing tobacco 71.4 million pounds; smoking tobacco, 60.5 million; and snuff, 26.4 million.

A summary of the various types used in the different tobacco products is shown below (imported types are shown in parentheses):

Product
$\begin{aligned} & \text { Cigarettes } \\ & \text { Flue-cured, burley, Maryland, (Oriental; Turkey, } \\ & \text { Greece) } \\ & \text { Filler, binder, wrapper, (Cuban, Philippine Is- } \\ & \text { lands), some Maryland, fire-cured, and dark } \\ & \text { air-cured. }\end{aligned}$

Chewing tobacco:

$\begin{array}{ll}\text { Plug } & \begin{array}{c}\text { Flue-cured, burley, dark air-cured, some Eire- } \\ \text { cured } \\ \text { One Sucker, burley, fire-cured } \\ \text { Fine-cut } \\ \begin{array}{c}\text { Loose leaf } \\ \text { chewing }\end{array} \\ \text { Cigley, Green River }\end{array} \\ \text { nufing tobacco } & \begin{array}{l}\text { Burley, flue-cured, dark air-cured, } \\ \text { Oriental } \\ \text { Fire-cured, some dark air-cured }\end{array}\end{array}$

\section{INTERNATIONAL TRADE}

Tobacco is produced and consumed in practically every country of the world and is one of the major items in international trade. World production was about 10 billion pounds in 1971 and continues at a near record. The United States is the leading producer with nearly 1.8 billion pounds in recent years, followed closely by Mainland China. Among the other important producing countries are India, USSR, Brazil, Pakistan, Japan, Turkey, Indonesia, Greece, Italy, Canada, Korea, Southern Rhodesia, and the Philippines. Most producing countries grow more than one type of leaf, but of ten supplement domestic production with imports of complementary types for blending in order to satisfy consumer tastes. Some countries produce a substantial surplus of tobacco over domestic needs and export large quantities. Some countries are both large producers and exporters, and also extensive importers. The United States falls in this last category. World exports currently amount to 1.8 billion pounds, roughly equal to one-fifth of total world production. 
International trade in tobacco reflects consumer preferences for various types of manufactured tobacco products. As tastes in consumption changed over a period of years, so did the demand for various types of tobacco. The popularity of snuffing in the 18th century gave way to pipe smoking and then to cigarettes. The requirement for leaf tobacco shifted accordingly from dark tobaccos in earlier years to flue-cured, light air-cured, and oriental types for cigarettes in more recent years. This changing pattern of consumer oreferences and the resulting popularity of various types of tobacco clearly affected the geography of tobacco production and trade on a worldwide scale.

International trade in tobacco is affected tremendously by governmental restrictions which have continued to increase over the years and now constitute one of the most important factors influencing such trade. The operation of government tobacco monopolies, tariff levels, import quotas, restrictions upon the use of foreign exchange, state trading, bilateral and compensation agreements, preferential duties, guaranteed markets, export subsidies, manipulation of currency exchange rates, mixing regulations, and economic unions, such as the recent European Economic Community--all have a direct, and usually restrictive, relationship on tobacco trade and tend to channel imports from selected sources.

The United States has been the world's most important producer and exporter of tobacco throughout its history. About one-third of the U.S. production currently moves into the export market. The major portion of this leaf is high-quality flue-cured and burley tobacco for use in the traditional American-blended cigarette in world markets. Turkey and Greece are the leading exporters of aromatic (oriental) tobacco and the United States is the principal importer of these types.

The United Kingdom is the largest individual leaf tobacco importer and now takes about one-fifth of all leaf tobacco moving in world trade. This leaf is mostly flue-cured for cigarette manufacture. The United Kingdom does not produce any tobacco. Germany, the second largest importer, also has a considerable domestic leaf production. The European Economic Community is the largest single area market for tobacco. This Economic Community produces about one-third of its annual requirements and must import to fulfill its needs. The United States is the third largest importer of tobacco, consisting of oriental leaf from Turkey and Greece which is used as a complementary ingredient in the American-blend cigaratte, cigar types for use in cigars, and smaller quantities of other kinds.

World trade in manufactured tobacco products is considerably less important than that in leaf. The extremely protectionist policies of governments in most areas favor their own domestic manufacturing industry. Cigarettes are the most important tobacco product moving in international trade but the volume is relatively small, compared with total production and consumption. Most of the total world output is consumed in the producing countries. for example, the United States, a major cigarette trader, exported about 32 billion cigarettes in 1971 which represented only 5 percent of the total produced. Significantly smaller quantities of other products including cigars, chewing tobacco, snuff and pipe tobacco move in world trade. 
The predominant factor influencing the tobacco industry today is the steadily increasing consumption of cigarettes, particularly the American-type blend, throughout much of the world. Its effects are apparent, not only in the increasing production of cigarette-type tobaccos for domestic consumption in many developing areas, but also in the export and import trade of cigarette tobaccos.

\section{UNITED STATES IMPORTS OF UNMANUFACTURED TOBACCO}

From earliest colonial times, tobacco has been one of the United States most important agricultural export commodities. It is currently exceeded in export value only by wheat, corn, and soybeans. In the beginning the overseas trade in tobacco was of such major importance that export statistics represent the only apparent record of production from 1618 to 1788 . Since 1870 tobacco exports have never fallen below 200 million pounds and have of ten been above 500 million pounds.

The total value of all United States unmanufactured leaf and products exported in 1971 was $\$ 683$ million, making a significant contribution to the overall U.S. balance of trade.

The United Kingdom was for many years the most important individual market for U.S. leaf tobacco, but the quantity and percentage going there has declined in recent years. The European Economic Community--a trade union comprised of Germany, Italy, France, the Netherlands, and Belgium-Luxembourg-is currently the major market area for U.S. tobacco, taking around one-third of U.S. leaf exports. The Common Agricultural Policy within the Community, which provides price supports and purchase incentives for domestic production and trade preferences for associated countries, is expected to have a significant impact on U.S. tobacco trade in the near future. The enlarging of the Common Market to include the U.K., Ireland, and other countries will have an additional bearing on our future exports. Other important markets are Sweden, Denmark, Sivitzerland, Japan, Australia, New Zealand, Thailand, and South Vietnam. Mainland China was an important market until 1948 when trade was halted. The recent resumption of trade with this country is not expected to produce any immediate benefits for U.S. tobacco growers.

All types of leaf produced in the United States enter into the export trade but flue-cured tobacco is the predominant type exported. This type currently accounts for more than 80 percent of total leaf exports. Exports of burley leaf, the second major type in U.S. production, is also used in blended cigarettes in a number of foreign countries, and about 8 to 10 percent of this type is normally exported. Fire-cured tobaccos led in production and exports during the 19 th century and until World War I. The extraordinary expansion of cigarettes has sharply reduced the demand for these types and a gradual decline continues.

Figure 44.--Tobacco being loaded for export at a Nortb Carolina terminal. $\longrightarrow$ Both bogsheads and containers are shown. 


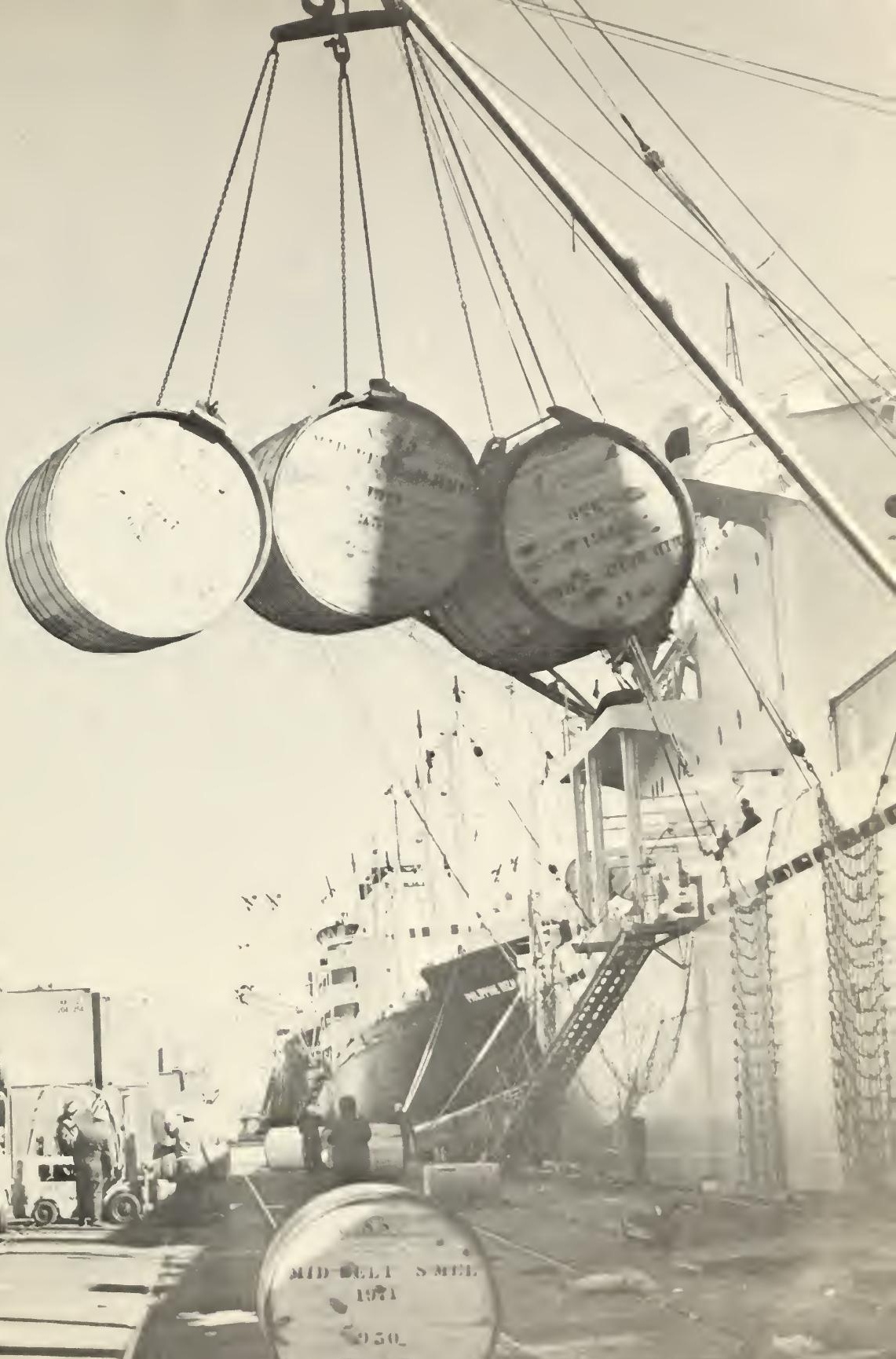


The principal export outlets in recent years for the three major kinds of U.S. leaf are as follows:

Flue-cured

United Kingdom

West fermany

Janan

Thailand

Netherlands

Australia

Belgium-Luxembourg
Burley

West Germany

Italy

Philippines

Portugal

Netherlands

Denmark

Sweden

Switzerland
Fire-cured

Netherlands

France

Congo (Kinshasa)

Belgium-Luxembourg

Norway

United Kingdom

West Germany

\section{UNITED STATES EXPORTS OF TOBACCO PRODUCTS}

The cigarette is by far the leading manufactured tobacco product exported from the United States. Relatively small quantities of smoking tobacco, chewing tobacco, and cigars also go into the export market. U.S.-manufactured cigarettes go into many foreign countries--the leading ones being Hong-Kong, Netherlands Antilles, Colombia, Spain, Kuwait, Panama, Netherlands, Switzerland, Paraguay, Italy, and Belgium-Luxembourg. In recent years, increased quantities of bulk smoking tobacco, blended and prepared for manufacture into cigarettes, has been exported.

Black Fat is a trade term applied to a unique tobacco form packed exclusively for export. Yost of it goes to West African countries, chiefly Nigeria and Ghana, with small quantities shipped to the West Indies. The product consists of One Sucker dark air-cured leaf and Kentucky and Tennessee fire-curen. The tobacco is carefully selected, particularly as to length, and tied onto hands of 4 to 6 leaves each. The leaves are put through a series of sweats until they are very dark and then packed under pressure. The final product is sprayed with a mineral oil to add sheen and packed in 1,000 pound crates for shinment. It is used mainly for pipe smoking by native populations but may be used as cherving tobacco or made into snuff. Some tribes use it as money.

\section{UNITED STATES I:YPORTS OF UNMANUFACTURED TOBACCO}

Although the United States is the world's largest producer and exporter of unmanufactured tobacco, it is also the third largest tobacco importing country in the Free World (exceeded only by the United Kingdom and Germany). This is true because of the great demand in this country for specific types of foreign tobacco, primarily oriental types used for blending in cigarettes. Most of this tobacco comes from Turkey and Greece. Cigar leaf types make up the remaining imnorts. The Philippine Islands now are the leading source of cigar type tobaccos followed by the Dominican Republic, Colombia, and Paraguay. The embargo against Cuba, imposed in February 1962, is still in effect. Stocks of Cuban leaf in the U.S. are virtually exhausted. 


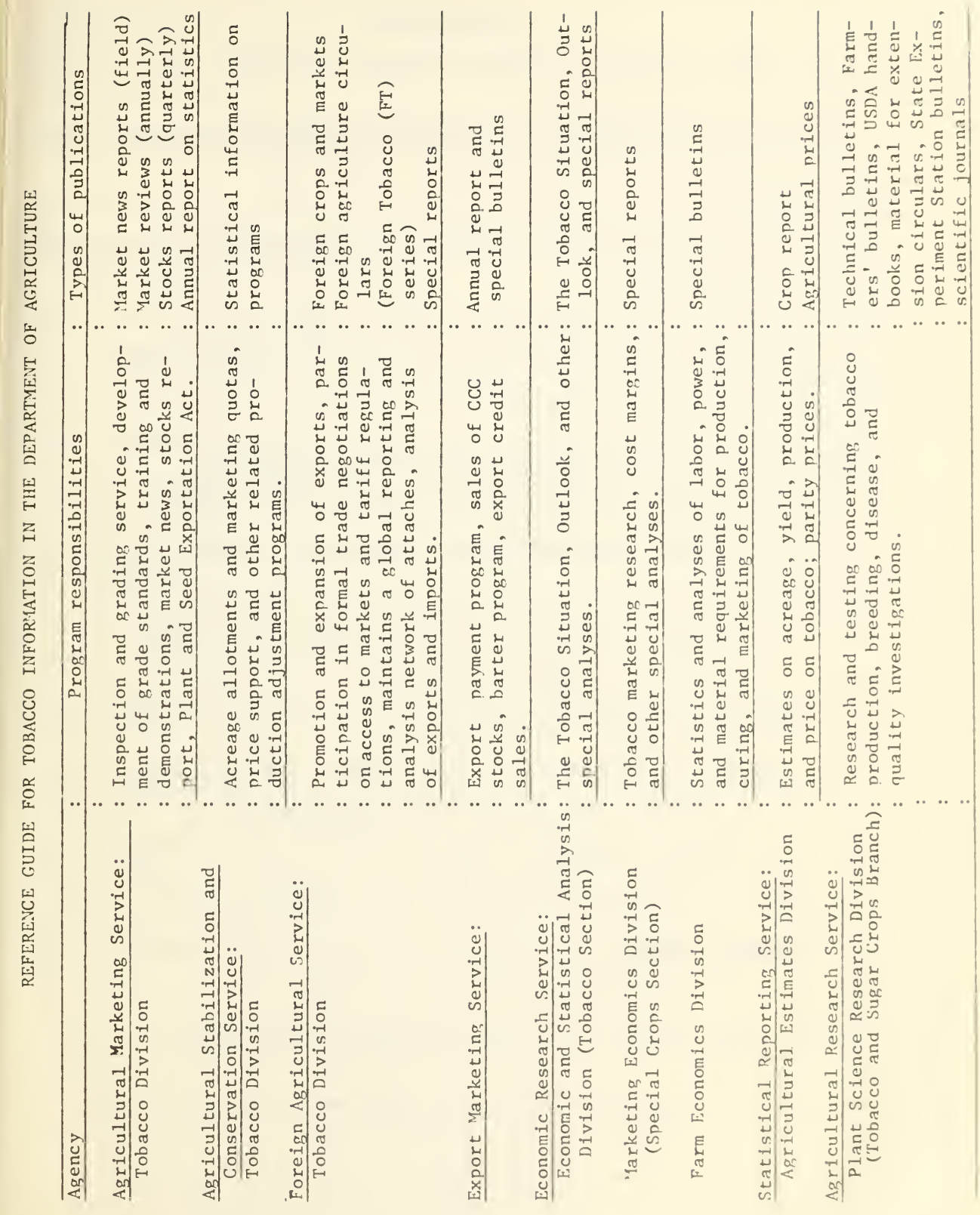




\section{BIBLIOGRAPHY}

The volume of published material on tobacco is enormous. The serious student can find some pamphlet or book on almost every facet of the industry.

Therefore, the following list is intended to direct the interested reader to sources of material, rather than individual publications.

\section{Principal sources}

Gage, Charles F., American tobacco types, uses, and markets, U.S. Department of Agriculture Cir. 249 (Rev. 1942). (Out of print but provides excellent background material.)

Garner, Jightman W., The Production of Tobacco, The Blakiston Co., Philadelphia (Rev. 1951). (Also out of print but a valuable reference work.)

Hawks, S. N., Jr., Principles of Flue-cured Tobacco Production, N.C. State University, Raleigh, N.C., 1970.

Federal and State publications from the following institutions:

University of Kentucky, Extension Service, Lexington, Ky • 40506

N.C. State University, Extension Service, Raleigh, N.C. 27607

Virginia Polytechnic Institute, Extension Service, Blacksburg, Va. 24060

University of Tennessee, Extension Service, Knoxville, Tenn. 37916

University of Maryland, College Park, Md. 20740

Clemson University, Clemson, S.C. 29631

Florida Department of Agriculture, Tallahassee, Fla. 33602

Connecticut Agriculture Experiment Station, New Haven, Ct.

University of Georgia, Athens, Ga. 30601

U.S. Department of Agriculture, Washington, D.C. 20250

Books of general interest

Akehurst, B.C., Tobacco, Humanities Press, Inc. (1963)

Middleton, Arthur Pierce, Tobacco Coast, 'Mariners' 'Iuseum (1953), Newport News, Va.

Brooks, Jerome E., The Highty Leaf, Little Brown and Co. (1952, New York. 
Robert, Joseph C., The Tobacco Kingdom, Duke University Press (1938), Durham, N.C.

Robert, Joseph C., The Story of Tobacco in America, Alfred A. Knopf (1949) New York.

Tilley, Nannie May, The Bright Tobacco Industry, 1860-1929, University of North Carolina Press (1948), Chapel Hill, N.C.

Heimann, Robert K., Tobacco and Americans, McGraw-Hill (1960), New York

Wagner, Susan, Cigarette Country. Tobacco in American History and Politics Praeger Publishers, New York (1971)

Sherman, Milton M., All About Tobacco. Sherman National Corp. (1970) New York

John, Raymond, Tobacco Dictionary, Philosophical Library (1954) New York

Other sources of information on the tobacco industry

Howard S. Cullman Library, Tobacco Merchants Assn. of the U.S., StatlerHilton, Room 63, 7th Avenue and 33rd Street, New York, N.Y. 10001

The Tobacco Institute, Inc., 1776 K Street, N.W., Suite 1200, Washington, D.C. 20006

Tobacco Associates, Inc., 1101 - 17th Street, N.W., Washington, D.C. 20036

Tobacco Tax Council, Box 8269, Richmond, Va. 23226

National Assn. of Tobacco Distributors, 360 Lexington Avenue, New York, N.Y. 10017

Cigar Manufacturers Assn. of America, Inc., 350 Fifth Avenue, New York, N.Y. 10001

Associated Tobacco Manufacturers, 910 - 17th Street, N.W., Washington, D.C. 20006

Smokeless Tobacco Council, Inc., 18 E. 48th Street, New York, N.Y. 10017 National Tobacco-Textile Museum, P.0. Box 541, Danville, Va. 24541 
The editors wish to express their gratitude to the following firms, organizations, and publications who have supplied data, comments, and photographs:

American Machine and Foundry Company

Associated Tobacco Manufacturers

Bayuk Cigars

Bloch Bros. Tobacco Company

Brown \& Williamson Tobacco Company

Cigar Manufacturers Association

Conwood Corporation

Conn-Mass Tobacco Cooperative

Dibrell Bros., Inc.

Flue-cured Stabilization Corp.

The Flue-cured Tobacco Farmer

North Carolina Port Authority

North Carolina State University

R. J. Reynolds Tobacco Company

The Tobacco Institute

Tobacco Merchants Association

University of Florida

University of Kentucky

Virginia Department of Agriculture

The Wilson, N.C., Daily Times

Within the Department of Agriculture, the text was reviewed by the Agricultural Stabilization and Conservation Service, Economic Research Service and Foreign Agricultural Service. 


\section{A SHORT SELECTION OF TOBACCO TERMINOLOGY}

Bright - Principally used as a reference to flue-cured tobacco such as "bright leaf", or "bright Virginia."

Case - (1) The condition of the tobacco with regard to its moisture content. Tobacco in proper keeping condition is said to be "in case." When too wet, it is in "high case."

(2) A specified amount of cigar tobacco packed into a wooden case for fermenting and storage.

Casing - Applying flavoring agents on blended tobacco during manufacturing

Cigar - A technical definition is perhaps not necessary, but a discussion of the several sizes of cigars is helpful:

(1) Blunt

(2) Cigari11o

(3) Corona

(4) Panate11a

(5) Perfecto

(6) Cheroot

(7) Stogie

(8) Little cigar
A slender cigar smaller than a corona but not as small as a cigarillo.

A very small thin cigar with a straight cut lighting end.

Generally applied to any "large" cigar with a straight-cut lighting end.

A somewhat long straight cigar, in proportion to its diameter, with an open lighting end.

A reference to any cigar, usually "large," which tapers from the center toward each end. There are many shapes and sizes of Perfecto cigars.

A cigar of simple construction and, usually, small size, open at both ends and made of tobaccos not commonly used in standard cigars.

A vernacular term for any cigar, especially an inexpensive brand. The term comes from the handmade product of Conestoga wagon drivers used for their own consumption and barter.

In shape and appearance closely resembling a cigarette but made with cigar tobaccos. 
Cigarette - Any filler of finely cut tobaccos rolled in paper may be termed a cigarette. There are two sizes made in the U.S.: "large" weighing more than three pounds per thousand, and "smal1" weighing less than three pounds per thousand. Most cigarettes are in the small category.

Dark - Usually a reference to those types of heavy tobaccos used in chewing and snuff products, such as "Dark-fired", "Dark air-cured"

Hogshead - The origin of this term is not known but it refers to a barre1like container originally used for storing liquids. The English standardized it at 63 gallons in 1423, but in practice, the capacity varies. It was adapted for storing and transporting tobacco from the beginning of the trade and is still preferred by the industry. A hogshead of tobacco usually measures 48 inches in length and diameter and contains 1,000 pounds.

Plug - The term is said to have originated in Kentucky or Missouri where settlers first soaked tobacco in honey and then "plugged" it tightly into holes bored in a green maple or hickory log. After the moisture was drawn out of the tobacco and the wood split, the "plug" or sweet chew was removed. Today it refers to a square or rectangular cake of tobacco which may be chewed or smoked.

Pool - (1) A vernacular term used in reference to various cooperatives organized by growers to market their tobacco in an orderly and profitable manner.

(2) Any of the 13 grower cooperatives which administer the price support program under contract with the Commodity Credit Corporation.

Sweating - The process of fermenting tobacco by natural or artificial means. Al1 cigar tobaccos undergo fermentation. The term is also erroneously used in reference to the aging process of cigarette tobacco.

Virginia - As in "bright," a general reference to flue-cured tobacco grown anywhere in the world. 



